MATHEMATICA CENTER FOR

STUDYING DISABILITY POLICY

\title{
Examining the Consequences of Poor Neonatal Health on the Family
}

\section{November 2019}

\author{
Dara Lee Luca* \\ Purvi Sevak
}

\section{*Corresponding author's contact information:}

955 Massachusetts Avenue

Cambridge, MA 02139

Telephone: (617) 588-6708

Email: DLeeLuca@mathematica-mpr.com

Reference Number: 40112.D-MP-18-06

The research reported herein was performed pursuant to a grant from the U.S. Social Security Administration (SSA) funded as part of the Disability Research Consortium. The opinions and conclusions expressed are solely those of the authors and do not represent the opinions or policy of SSA or any agency of the Federal Government. Neither the United States Government nor any agency thereof, nor any of their employees, makes any warranty, expressed or implied, or assumes any legal liability or responsibility for the accuracy, completeness, or usefulness of the contents of this report. Reference herein to any specific commercial product, process, or service by trade name, trademark, manufacturer, or otherwise does not necessarily constitute or imply endorsement, recommendation or favoring by the United States Government or any agency thereof.

This draft paper is intended for review and comments only. It is not intended for citation, quotation, or other use in any form without the permission of the author(s). 
This page has been left blank for double-sided copying. 


\section{CONTENTS}

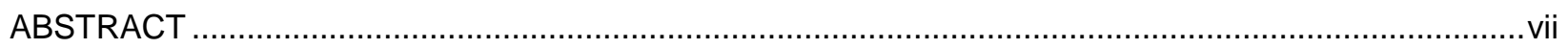

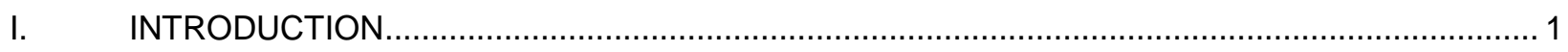

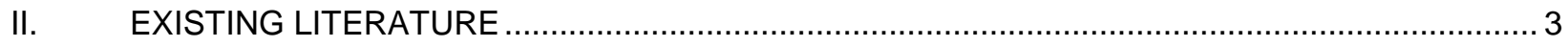

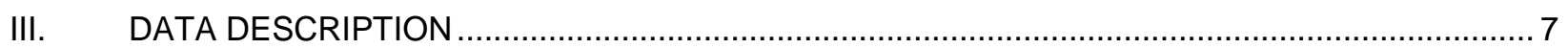

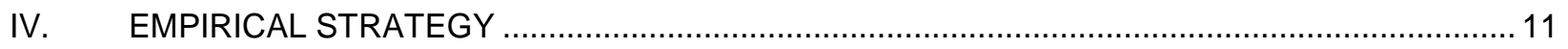

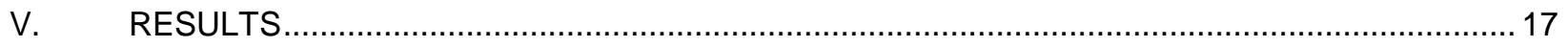

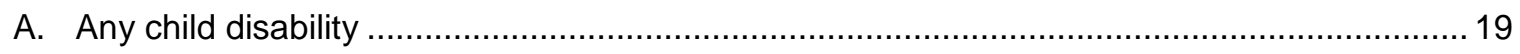

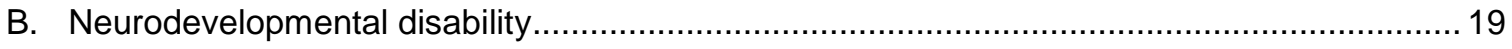

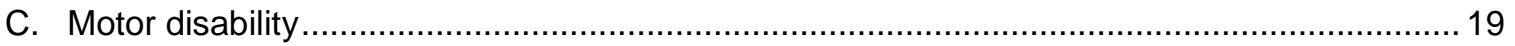

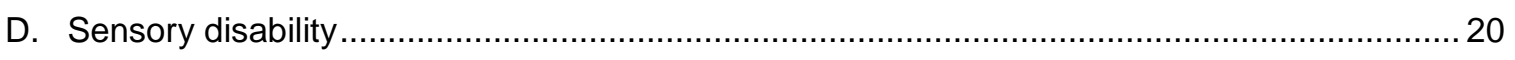

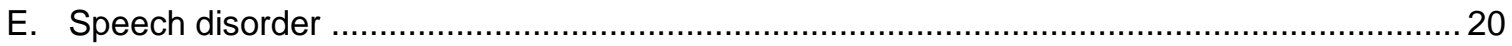

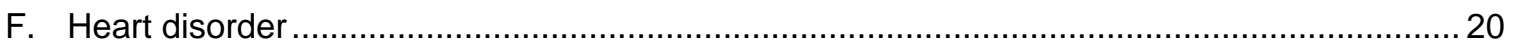

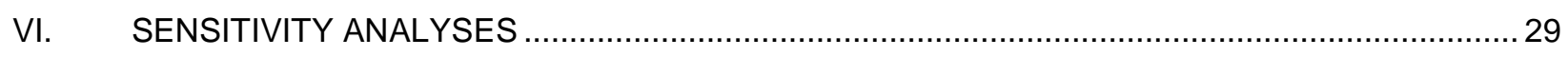

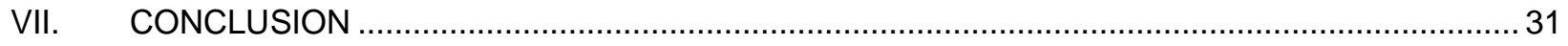

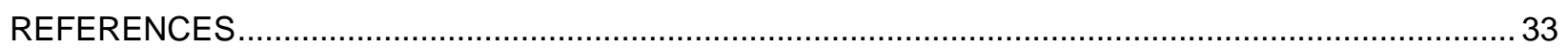

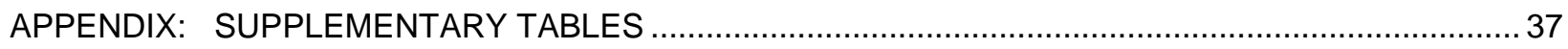

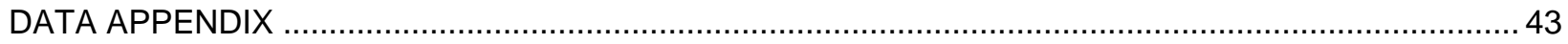


This page has been left blank for double-sided copying. 


\section{TABLES}

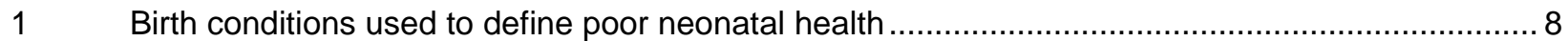

2 Differences in pre-birth measures, weighted and unweighted ............................................... 14

$3 \quad$ Summary statistics of key variables by wave ......................................................................... 16

$4 \quad$ Impact of poor neonatal health and subsequent child disability .............................................. 18

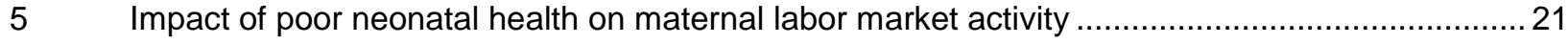

$6 \quad$ Impact of poor neonatal health on benefit receipt................................................................ 24

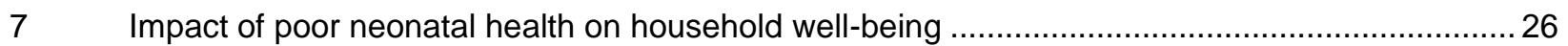

8 Sensitivity analyses: using different definitions of poor neonatal health ................................... 30 
This page has been left blank for double-sided copying. 


\section{ABSTRACT}

\section{Project Number}

D-MP-18-06

\section{Title}

Examining the Consequences of Poor Neonatal Health on the Family

\section{Authors}

Dara Lee Luca and Purvi Sevak

\section{Date}

June 2019

\section{Key Findings and Policy Implications}

Using a 15-year panel from the Fragile Families \& Child Wellbeing Study, we examine the consequences of poor birth outcomes for both the child and her family. We apply entropy balancing and weighting methods to account for differences between families who have a child with poor neonatal health versus those who do not. We find that children with poor neonatal health are more likely to be diagnosed with a disability and to receive Supplemental Security Income. Mothers who have children with poor neonatal health are more likely to reduce labor force participation at both the intensive and extensive margins when the child is young. Further, they are more likely to receive benefits from the Supplemental Nutrition Assistance Program and the Temporary Assistance for Needy Families program. We find no significant effects of poor neonatal health on maternal mental health or household income. However, parents who have children with poor neonatal health are significantly less likely to remain married or cohabiting. 
This page has been left blank for double-sided copying. 


\section{INTRODUCTION}

Despite the well-documented evidence that poor neonatal health is linked to an array of worse adult outcomes (Almond, Chay, \& Lee, 2005; Black, Devereux, \& Salvanes, 2007; Figlio, Guryan, Karbownik, \& Roth, 2014; Oreopoulos, Stabile, Walld, \& Roos, 2008), critical gaps remain in our understanding of the consequences of poor birth outcomes, which can include low birth weight, preterm birth, and other abnormal birth conditions. In particular, we have limited knowledge of the scope of effects of poor neonatal health on the family. A child with poor neonatal health may require more financial resources and parental time investment than a child born without any complications. If the economic toll on the family is substantial, then the adverse effects of poor birth outcomes on the child may be significantly compounded. Moreover, the prevalence of poor birth outcomes is higher among low-income mothers (National Research Council and Institute of Medicine, 2000). Children from low-income families generally have limited access to care and credit, and even those with insurance might face additional barriers to adequate care and treatment (Van Cleave, Gortmaker, \& Perrin, 2010). Disparities in poor birth outcomes can therefore have persistent and magnifying effects on income and health inequality. Understanding the spillover effects of poor neonatal health on families is critical in formulating policies to support the well-being of these children and their families.

In this paper, we leverage administrative birth record data merged with longitudinal survey data from the Fragile Families and Child Wellbeing Study to examine the consequences of poor neonatal health on both the child and the family. The Fragile Families Study follows, from birth to age 15 over six survey waves, about 5,000 children born between 1998 and 2000, and their parents. We examine a comprehensive range of outcomes that measure household well-being, including child health, maternal labor supply, safety net program participation, household income, poverty, maternal mental health, and parental relationship. Because families who have a child with a poor birth outcome may be systematically different from those who do not, we use entropy balancing and weighted least squares to adjust for observable differences between treated and non-treated families (Hainmuller, 2012).

We present several key findings. One-fifth of children born to urban families have a poor birth outcome. The most common abnormal birth conditions are low birth weight (10.6 percent), followed by assisted ventilation for more than 30 minutes ( 7.2 percent) and birth injury (6.8 percent). Mothers who experience a poor birth outcome-who we will refer to as being "treated" henceforth - are notably different from those who do not in a number of pre-birth dimensions. For example, treated mothers exhibit higher rates of psychosocial risks during pregnancy (e.g., substance use and involvement in the criminal justice system), which highlights the need for an empirical approach that takes into account the endogeneity of poor birth outcomes. We show that using entropy balancing greatly enhances comparability between treated and non-treated families along all examined measures with respect to both first and second moments.

Our estimates using weights constructed from entropy balancing suggest that children who had poor neonatal health are much more likely to be diagnosed with a disability, especially one related to neurodevelopmental disorders. We find evidence that treated mothers decrease labor force participation at both the intensive and the extensive margins, especially when the child is young. Treated children are also much more likely to receive Supplemental Security Income (SSI), and treated mothers are more likely to receive benefits from the Supplemental Nutrition 
Assistance Program (SNAP) and the Temporary Assistance for Needy Families (TANF) program. Household income among treated families is on average lower, but the difference is not statistically significant in any wave. Similarly, treated households are not significantly more likely to be in poverty, possibly as a result of the additional financial support they receive from safety net programs. Parents of children with poor neonatal health are much less likely to be married or cohabitating in any wave. The probability of maternal depression, on the other hand, does not appear to be affected significantly by poor neonatal health. Results are consistent when using alternate definitions of poor neonatal health, including when we consider only "exogenous" abnormal birth conditions that were unlikely to be caused by maternal prenatal behavior.

The rest of the paper proceeds as follows. Section II briefly surveys the related literature. Section III describes the data, followed by a discussion of the empirical strategy in Section IV. Section V reports and discusses the key findings. Section VI offers several exercises to test the sensitivity of our results. Section VII concludes. 


\section{EXISTING LITERATURE}

Many studies have examined the relationship between neonatal health (commonly proxied by birth weight) and later outcomes of the child. Because of concerns about endogeneity-low birth weight may be correlated with other measures, such as socioeconomic background or genetic endowment, that affect the dependent variable - the more rigorous studies within this literature tend to use twin or sibling fixed effects approaches to identify causal effects. Almond et al. (2005) examined the short-term effects of birth weight using twin data in the United States, and found that within-twin fixed effects estimates of birth weight on hospital costs (negative), infant mortality (negative), and Apgar scores (positive), are significant but much smaller in magnitude than ordinary least squares (OLS) estimates would suggest. Black et al. (2007) used a similar approach to examine the effects of birth weight on both short-run and long-run outcomes for twins in Norway. They found that while short-run twin fixed effects estimates are much smaller than OLS estimates, the effects on longer-run outcomes (such as adult height, IQ, earnings, and education) are significant and similar in magnitude to OLS estimates. Oreopoulos et al. (2008) used a large sample of both siblings and twins from Canada to find that poor infant health is a strong predictor of educational and labor force outcomes, as well as dependence on social assistance.

The existing literature makes it clear that poor neonatal health has a permanent adverse effect on socioeconomic and health outcomes. Therefore, it is important for a variety of policy reasons to know how poor neonatal health affects child development, and whether there are any public policies that might help to remediate the negative relationship between early poor health and later-life outcomes. Along this vein, Figlio et al. (2014) used merged birth and school records for all children born in Florida to study the relationship between birth weight and cognitive development. Using twin and sibling fixed effects models, they found significant negative effects of low birth weight on cognitive development, with effects being similar across socioeconomic backgrounds. They conclude that the effects of early health on adult outcomes are therefore set very early. In a recent paper, Elder, Figlio, Imberman, and Persico (2019) assessed the effects of neonatal health on the identification of childhood disabilities using the same Florida birth data and a similar empirical approach of sibling and twin fixed effects models. They found that infant health influences multiple measures of disability and grade repetition in school. Their results suggest that disability might be one mechanism through which birth weight affects long-run human capital outcomes.

Another strand of research examines the relationship between child health and other household outcomes. Kuhlthau and Perrin (2001) conducted a cross-sectional study using data from the 1994 National Health Interview Survey to show that having a child with poor health status is associated with reduced employment of parents. Using data from the Panel Study of Income Dynamics, Gould (2004) found that this cross-sectional relationship is significant for time-intensive or unpredictable medical conditions (for example, autism, diabetes, and heart conditions) but not for other conditions. Powers (2003) used data from the Survey of Income and Program Participation to examine the relationship between maternal labor supply (measured in levels and changes over a two-year horizon) and having a child with a disability, and found that child disability is associated with a lower probability of entering the labor force for female heads but not for married mothers. Controlling for labor supply prior to the child's birth, along with individual and local area characteristics, Corman et al. (2005), using data from the Fragile 
Families Study, estimated that having a child in poor health reduces both the probability the mother works and the hours worked among working mothers when their child is around age 1. Luca and Sevak (2018) used a child fixed effects model and data from the Fragile Families Study to show that maternal labor force participation decreases at the intensive margin prior to the identification of child disability, and decreases at the extensive margin after identification.

Other studies have examined the relationship between child disability and benefit receipt. Reichman, Corman, and Noonan (2004) used data from the Fragile Families Study to show that when the child was between 1 and 1.5 years old, mothers with children in poor health were more likely than those with healthy children to rely on TANF and/or SSI. Guldi, Hawkins, Hemmeter, and Schmidt (2018) examined a slightly different question about the impact of child SSI receipt among a narrower population of extremely-low-birth-weight babies and found that eligibility for SSI shifts maternal labor supply from full-time to part-time, as well as improves child outcomes in several dimensions.

Child disability is associated with other poor household economic outcomes as well. Using data from multiple sources, Case, Lubotsky, and Paxson (2002) documented a strong relationship between family income and child health. Using the repeated waves of the NLSY79, Porterfield and Tracy (2003) demonstrated that families with at least one child born with a disability are more likely to be in poverty three to six years after the child is born, relative to families without a disabled child, even though their characteristics pre-birth were not significantly different.

Finally, several studies have also examined the effects of child health on parental relationship status. Reichman et al. (2004) used the Fragile Families data to find that having an infant in poor health reduces the likelihood that parents will live together by the time the child is between 12 to 18 months old, particularly among parents with low socioeconomic status. Hartley et al. (2010) found that parents of children with an autism spectrum disorder had a higher rate of divorce through the child's adolescence than a matched comparison group of parents of children without disabilities. Similarly, Swaminathan, Alexander, and Boulet (2006) found that parents of a very-low-birth-weight infant have two-fold higher odds of divorce or separation two years after delivery when compared with parents of a child with a birth weight greater than 1,500 grams.

Our study contributes to the existing literature in several ways. First, we shed light on one important channel through which poor infant health can lead to worse adult outcomes: spillover effects on the family. By understanding how poor neonatal health affects these key household outcomes, the findings could provide insight on policies aimed to alleviate the negative relationship between early poor health and later-life outcomes. Second, the data we use allow us to examine the trajectories of outcomes from the child's birth to age 15, whereas many existing studies focus on either very short horizons or adult outcomes. By using six waves of longitudinal data spanning 15 years, we can shed light on how a poor birth outcome can affect the family from the child's birth through her teen years. Third, we analyze a comprehensive range of outcomes that capture the economic circumstances and well-being of the families: maternal earnings, work hours, employment, household income, public-transfer receipt, poverty, household dissolution, and maternal depression. In taking this broader perspective, we obtain a more inclusive picture of how families fare in the face of a child's adverse birth. Finally, by using entropy balancing, we generate weights that allow covariate balancing between treated and nontreated families on a much larger set of pre-birth characteristics (more than 60 variables) than 
what was used in previous literature. We show that although treated mothers are not significantly different in many commonly examined demographic characteristics, such as age and education, they exhibit stark differences in medical and psychosocial risk factors that we obtained from the confidential medical record data, such as involvement in the criminal justice system, experience with domestic violence, and substance use during pregnancy. One important limitation of our empirical approach is that we cannot control for unobservable characteristics, such as in utero environment or genetic factors, as in the twin studies. However, while the unique circumstances surrounding identical twinning provide researchers with useful leverage in questions of causation, the generalizability of twin studies is also limited (Conley et al. 2006). We believe that the extensive set of variables we can control for in our analysis, the fact that we can examine a comprehensive range of household outcomes, and the fact that we can track the outcomes from the child's birth through early adolescence makes this paper a novel and useful contribution to the literature. 
This page has been left blank for double-sided copying. 


\section{DATA DESCRIPTION}

To examine how poor neonatal health affects the family, we use data from the Fragile Families and Child Wellbeing Study, a rich, longitudinal data set that follows a cohort of 5,000 children born between 1998 and 2000 from birth to around age 15. The survey is designed to be representative of births in cities with a population of 200,000. A goal of the study was to obtain data to develop an understanding of how children fare when born into families that are "fragile" (more vulnerable to poverty and breakup), and how policies and environmental conditions affect these families. With more than half the births in the sample covered by Medicaid, a large proportion of the sample is poor or near poor, which provides a unique opportunity to study how a child's adverse birth outcome could affect this especially vulnerable population.

The survey currently has six waves of data. The baseline interview ("wave 1") took place in the hospital at the time of the focal child's birth. Follow-up interviews occurred when the focal child was age 1 ("wave 2"), 3 ("wave 3"), 5 ("wave 4"), 9 ("wave 5"), and 15 ("wave 6"). The study used a complex, multi-stage clustered sampling design, with an oversample of unmarried parents. Although births among unmarried females were oversampled, the data, when weighted or regression adjusted, represent all hospital births in large cities between 1998 and 2000 (see Reichman et al., 2001 for details). We use the city weighting scheme to provide a representative picture of children from the 22 cities that participated in the survey.

The study has several features that make it particularly valuable for assessing the effects of a poor birth outcome on the household. The Fragile Families Study collected crucial administrative medical-record data that were drawn from birth hospitalization records for mothers and focal children, and we use the birth record data to define poor neonatal birth. These data, which are available for 3,681 births, include detailed information on birth weight, gestational age, chromosomal abnormalities, and other indicators of abnormal birth conditions. In addition to low birth weight and preterm birth (conditions that are typically used in the literature to define a poor birth outcome), we include other abnormal birth conditions (e.g., genetic conditions) or birth circumstances that are associated with serious negative health consequences (e.g., requiring assisted ventilation for more than 30 minutes). ${ }^{1}$ Table 1 reports the types of birth conditions that we use to define poor neonatal health and the frequency of those conditions in the sample. The most common types of abnormal birth conditions are (1) low birth weight, followed by (2) respiratory issues that require assisted ventilation for more than 30 minutes, and (3) preterm birth. The conditions listed in Table 1 are not mutually exclusive (e.g., infants born preterm are often low birth weight, and such infants are more likely to have underdeveloped lungs and concomitant breathing problems.) In Section VI, we test the sensitivity of the results to two alternate definitions of poor neonatal health.

We are particularly interested in understanding the association between poor neonatal health and the likelihood of being diagnosed with a disability or chronic health condition in later childhood. To define child disability, we use health information reported by the primary caregiver. The questions and specific conditions vary somewhat from wave to wave, partly to reflect the age of the children. In the second and third waves, when the focal child is about 1 and

\footnotetext{
${ }^{1}$ We determined which conditions to include by consulting with a pediatrician whose research focuses on the health and well-being of children living in poverty.
} 
3, respectively, the primary caregiver is asked whether the child has any disabilities, and after an affirmative binary response, the respondent is further asked to classify the disability type among a given list (refer to the data appendix for the full list). Starting in the fourth wave, the pertinent question changed to "Has a doctor or health professional ever told you that (CHILD) has any of the following health conditions?" Questions about attention-deficit/hyperactivity disorder (ADHD) and autism were added beginning in wave 4 when the child was about 5 . The addition in later waves makes sense because it is often impossible to diagnose such conditions at earlier ages. We broadly code the child as having a diagnosed disability if the primary caregiver responded "yes" to the binary question in waves 2 and 3 and to any of the listed disabilities in wave 4 onward. The data appendix provides a detailed description of the survey questions and the types of disabilities covered in each wave.

\section{Table 1. Birth conditions used to define poor neonatal health}

\begin{tabular}{lc} 
Birth conditions & Percentage (\%) \\
Respiratory system & \\
Assist ventilation $>30$ min & 7.23 \\
Hyaline membrane disease/respiratory distress syndrome & 3.26 \\
Central nervous system & \\
Hydrocephalus & 0.19 \\
Microcephalus & 0.16 \\
Seizures & 0.24 \\
Spina bifida/meningocele & 0.00 \\
Other central nervous system & 1.77 \\
Circulatory system & 0.00 \\
Heart malformations & 0.60 \\
Renal/genital/urinary system & \\
Renal agenesis & 0.00 \\
Musculoskeletal/integumental & \\
Cleft lip/palate & \\
Club foot & 0.16 \\
Chromosomal & 0.05 \\
Down syndrome & \\
Other chromosomal & 0.19 \\
Other & 0.43 \\
Birth injury & \\
Drug withdrawal & \\
Birth weight <2,500 g & 6.79 \\
Preterm <32 weeks & 2.74 \\
Poor neonatal health & 10.64 \\
Number of observations & 2.23 \\
\hline No: Brth cond/ins ate & 20.35 \\
\hline
\end{tabular}

Note: Birth conditions are not mutually exclusive. Means are estimated using the city sample weights.

In addition to child health, we measure the effects of poor neonatal health on an encompassing range of outcomes that capture household well-being, including maternal labor supply, earnings, household benefit receipt, household income, financial distress, maternal depression, and parental marital status. For maternal labor market activity, the survey asks about labor market status, including whether currently working, hours of work, and earnings at each 
job. ${ }^{2}$ The study also contains detailed information on household participation in various safety net programs: TANF, SNAP, SSI, and other forms of public assistance, such as unemployment insurance and workers' compensation. ${ }^{3}$ We also examine the associations of having an infant born in poor health and household income, as well as household poverty status. ${ }^{4}$

Finally, we examine whether poor neonatal health affects maternal mental health, which we consider to be a novel contribution to the literature. Recent research has shown that as many as one in seven mothers experience perinatal mood and anxiety disorders, and the cost of untreated maternal depression is high in the United States (Luca, Garlow, Staatz, Margiotta, \& Zivin, 2019). The psychological stress of having a child with a poor birth outcome is conceivably large, and could be further exacerbated among the lower socioeconomic status families that make up the Fragile Families sample. It is therefore of policy interest to examine whether maternal mental health is affected by poor neonatal health. The Fragile Families Study constructed two measures of maternal depression (conservative and liberal) based on the mother's responses to a standard series of questions intended to measure the severity of depression. We use the conservative definition as the dependent variable.

\footnotetext{
${ }^{2}$ While the Fragile Families Study also surveys fathers (even if they do not reside in the same household), we focus on maternal labor market outcomes because of the much higher rate of father attrition from the survey.

${ }^{3}$ SSI is a disability program that provides cash benefits to children who medically qualify as disabled under SSA rules and whose families have little income or resources. TANF is the nation's primary need-based welfare program for single, unemployed, or underemployed low-income mothers. SNAP is a means-tested program that provides eligible households with monthly supplements to purchase food.

${ }^{4}$ Refer to the Data Appendix and Fragile Families public-use data guide for more information on income and poverty measures: https://fragilefamilies.princeton.edu/sites/fragilefamilies/files/ff_public_guide_0to5.pdf.
} 
This page has been left blank for double-sided copying. 


\section{EMPIRICAL STRATEGY}

The key challenge in our empirical analysis is that the mothers and families who have a child born in poor health ("treated" families) may differ systematically from mothers and families who do not. For example, women who are more educated might be more likely than less-educated women to obtain prenatal care and less likely to have a child with preterm birth. The effect of having a child with a poor birth outcome might therefore be biased in a research design that does not take into account the potential endogeneity of having an adverse birth outcome.

Our analysis uses weighting methods with entropy balancing to flexibly control for the observed differences between mothers who did and did not have a child with a poor birth outcome. While this approach naturally cannot rule out selection based on unobservable factors, we can include an extensive list of pre-birth covariates to model the probability of having an infant with poor neonatal health.

To achieve covariate balance in a large set of measures between treated and non-treated households, we use entropy balancing, which can be thought of as a generalization of the conventional propensity score weighting approach where the researcher first estimates the unit weights with a logistic regression and then conducts balance checks to see whether the estimated weights help enhance comparison between treatment and comparison groups. However, in practice, such estimated propensity score weights can fail to balance the covariate moments, even when manually cycling through multiple iterations between propensity score modeling, matching, and balance checking to search for a suitable balancing solution. Researchers have found that slight misspecification of the propensity score model can result in substantial bias of estimated treatment effects (Kang and Schafer 2007; Smith and Todd 2005). Entropy balancing works "backward" by estimating the weights directly from the imposed balance constraints. The entropy-balancing scheme then searches for a set of weights that satisfy the balance constraints, while striving to keep the weights as close as possible to the set of uniform base weights in order to retain efficiency for the subsequent analysis. A key advantage of entropy balancing is that it ensures balance on all covariate moments included in the reweighting, which precludes the need for continual balance checking and iterative searching over propensity score models that may stochastically balance the covariate moments (Hainmueller, 2012). ${ }^{5}$

We conduct entropy balancing to generate separate weights for each wave and each outcome separately to ensure covariate balance in both first and second moments for each model that is being estimated. We incorporate the city sampling weights into both the entropy reweighting scheme and the outcomes analysis to take into account the complex sampling design and response rates over waves (Ridgeway, Kovalchik, Griffin, \& Kabeto, 2015). ${ }^{6}$ To the extent there may be varying missingness across outcomes, or differential attrition for treated and non-treated

\footnotetext{
${ }^{5}$ We used the ebalance package in Stata to conduct the entropy balancing (Hainmueller and Xu, 2013).

${ }^{6}$ National sample weights were not available for six cities (see Carlson, 2008 for a discussion of the construction of the weights). Since the degree of missingness in the national weights is much higher, we use the city weighting scheme to preserve the sample size. The results are qualitatively consistent when using the national weighting scheme.
} 
families, reweighting helps ensure covariate balance in each model that is being estimated (i.e., baseline covariates will be balanced for all measures in each model, regardless of differential attrition). We include a large set of baseline covariates that are potentially associated with the treatment and outcome for entropy balancing (Table 2).

We then use the unit weights determined through entropy balancing to generate weighted least squares estimates. Following Rosenbaum and Rubin (1983), our main interest is in the estimation of the average treatment effect on the treated (ATT) for the sample of treated women, so that the weights for treated women in the sample are 1 and the weights for non-treated women are $\widehat{w}_{i}$, constructed through entropy balancing. For the estimation of the ATT, the outcome variable, $Y_{i t}$, is regressed on the treatment dummy variable, PoorBirthOutcome ${ }_{i}$, applying the individual weights, $\widehat{w}_{i}$. Intuitively, observations are weighted so that greater weight is given to units that are more similar to the treated units. We estimate the outcome model for each outcome separately by wave, using weighted least squares models and including hospital and state (at baseline) fixed effects. Robust standard errors are clustered by the primary sampling unit.

We present descriptive statistics for baseline characteristics that are used to estimate the weights through entropy balancing in Table 2 . It is evident that families who experience an adverse birth outcome are different at baseline from those who do not. In terms of sociodemographic characteristics, treated mothers are more likely to be Black, less likely to be Hispanic, less likely to be married, and more likely to work. Interestingly, treated mothers are more educated and tend to have higher household income, which reflects both their higher earnings and their greater share of benefits from a safety net program. More revealingly, treated mothers have higher rates of many psychosocial flags typically not observed in survey data, which could confound both the likelihood of poor neonatal health and the outcomes of interest. For example, treated mothers are more likely to be reported (in birth record data) as having suspected parenting inadequacy, to experience domestic violence, and to be involved in the criminal justice system. These differences highlight the nuanced differences between treated and non-treated families and the need for an empirical strategy to improve comparability between the two groups. After we apply entropy balancing, covariate balance is achieved as expected: standardized differences shrink to zero, and the variance ratio becomes 1 for all baseline measures, demonstrating the strength of entropy balancing to facilitate covariate balancing.

To see how characteristics of families in the Fragile Families Study change in the years since the child's birth, we examine summary statistics of key variables in the subsequent waves (Table 3). The variables shown in Table 3 are somewhat different from the baseline variables presented in Table 2, because the baseline survey asked questions that were different than those asked in the subsequent waves, over which the surveys also changed. For example, SSI receipt by household member was no longer asked in the sixth wave but was instead grouped with other types of benefits. Overall, the statistics show slight upward trends in earnings and household income over the age of the child. Notably, there is a somewhat larger jump in earnings and household income between the fifth and sixth wave than between the other waves. This can perhaps be explained in part by the fact that there were six years between those two waves versus four years between the fourth and fifth waves (and even shorter intervals between prior waves). ${ }^{7}$

\footnotetext{
${ }^{7}$ The means for income and earnings are substantially lower when we do not use the sampling weights, which suggests that there could be differential attrition between households who make more and those who earn less.
} 
We next examine whether the trajectories of these outcomes vary significantly between families who have a child born with poor neonatal health and those who do not.

Further, treated families are about 5 percentage points more likely than non-treated families to attrite by wave 6 . Entropy reweighting helps address bias caused by differential attrition, but we advise caution when interpreting the wave 6 results. 
Table 2. Differences in pre-birth measures, weighted and unweighted

\begin{tabular}{|c|c|c|c|c|c|c|c|}
\hline \multirow[b]{2}{*}{ Baseline measure } & \multirow[b]{2}{*}{$\begin{array}{c}\text { Treated } \\
\text { mean }\end{array}$} & \multicolumn{3}{|c|}{ Unweighted } & \multicolumn{3}{|c|}{ Weighted } \\
\hline & & $\begin{array}{l}\text { Control } \\
\text { mean }\end{array}$ & $\begin{array}{l}\text { Std. } \\
\text { diff. }\end{array}$ & $\begin{array}{l}\text { Variance } \\
\text { Ratio }\end{array}$ & $\begin{array}{l}\text { Control } \\
\text { mean }\end{array}$ & $\begin{array}{l}\text { Std. } \\
\text { diff. }\end{array}$ & $\begin{array}{l}\text { Variance } \\
\text { Ratio }\end{array}$ \\
\hline \multicolumn{8}{|l|}{ Age of mother (omitted category $=15-19$ ): } \\
\hline $20-24$ & 0.23 & 0.29 & -0.14 & 1.16 & 0.23 & 0.00 & 1.00 \\
\hline $25-29$ & 0.24 & 0.25 & -0.03 & 1.04 & 0.24 & 0.00 & 1.00 \\
\hline $30-34$ & 0.15 & 0.22 & -0.19 & 1.34 & 0.15 & 0.00 & 1.00 \\
\hline$>35$ & 0.16 & 0.09 & 0.20 & 0.60 & 0.16 & 0.00 & 1.00 \\
\hline Mother is non-Hispanic Black & 0.40 & 0.31 & 0.17 & 0.90 & 0.40 & 0.00 & 1.00 \\
\hline Mother is Hispanic & 0.26 & 0.34 & -0.18 & 1.16 & 0.26 & 0.00 & 1.00 \\
\hline Mother has HS/GED & 0.29 & 0.32 & -0.07 & 1.06 & 0.29 & 0.00 & 1.00 \\
\hline Mother has some college & 0.18 & 0.20 & -0.04 & 1.07 & 0.18 & 0.00 & 1.00 \\
\hline Mother has college degree or above & 0.21 & 0.15 & 0.16 & 0.75 & 0.21 & 0.00 & 1.00 \\
\hline Parents are married & 0.43 & 0.53 & -0.21 & 1.01 & 0.43 & 0.00 & 1.00 \\
\hline Mother's health is excellent & 0.33 & 0.32 & 0.03 & 0.97 & 0.33 & 0.00 & 1.00 \\
\hline Mother worked last year for pay & 0.70 & 0.68 & 0.05 & 1.04 & 0.70 & 0.00 & 1.00 \\
\hline $\begin{array}{l}\text { Mother's hours worked last year } \\
\text { Mother's weekly earnings (omitted } \\
\text { category = Quartile 1) }\end{array}$ & 24.53 & 24.76 & -0.01 & 1.09 & 24.52 & 0.00 & 1.00 \\
\hline Quartile 2 & 0.21 & 0.17 & 0.11 & 0.83 & 0.21 & 0.00 & 1.00 \\
\hline Quartile 3 & 0.17 & 0.22 & -0.13 & 1.21 & 0.17 & 0.00 & 1.00 \\
\hline Quartile 4 & 0.30 & 0.26 & 0.08 & 0.92 & 0.30 & 0.00 & 1.00 \\
\hline Parents are cohabitating & 0.26 & 0.23 & 0.07 & 0.91 & 0.26 & 0.00 & 1.00 \\
\hline $\begin{array}{l}\text { Mother participates in safety net program } \\
\text { Mother's primary insurance coverage }\end{array}$ & 0.35 & 0.30 & 0.11 & 0.92 & 0.35 & & 1.00 \\
\hline $\begin{array}{l}\text { is Medicaid } \\
\text { Mother's primary insurance coverage }\end{array}$ & 0.59 & 0.57 & 0.05 & 1.01 & 0.59 & 0.00 & 1.00 \\
\hline $\begin{array}{l}\text { is private } \\
\text { Household income (omitted category: < }\end{array}$ & 0.32 & 0.35 & -0.05 & 1.03 & 0.32 & 0.00 & 1.00 \\
\hline$\$ 4,999)$ & & & & & & 0.00 & \\
\hline$\$ 5,000-\$ 9,999$ & 0.10 & 0.10 & 0.01 & 0.97 & 0.10 & 0.00 & 1.00 \\
\hline$\$ 10,000-\$ 14,999$ & 0.10 & 0.11 & -0.05 & 1.13 & 0.10 & 0.00 & 1.00 \\
\hline$\$ 15,000-\$ 19,999$ & 0.09 & 0.09 & 0.00 & 0.99 & 0.09 & 0.00 & 1.00 \\
\hline$\$ 20,000-\$ 24,999$ & 0.26 & 0.19 & 0.15 & 0.81 & 0.26 & 0.00 & 1.00 \\
\hline$\$ 25,000-\$ 34,999$ & 0.13 & 0.14 & -0.02 & 1.04 & 0.13 & 0.00 & 1.00 \\
\hline$\$ 35,000-\$ 49,999$ & 0.12 & 0.15 & -0.08 & 1.17 & 0.12 & 0.00 & 1.00 \\
\hline$>\$ 50,000$ & 0.12 & 0.12 & 0.00 & 1.01 & 0.11 & 0.00 & 1.00 \\
\hline Household poverty status & 0.27 & 0.30 & -0.06 & 1.05 & 0.27 & 0.00 & 1.00 \\
\hline $\begin{array}{l}\text { Grandmother lives in the household } \\
\text { Number of existing children (omitted }\end{array}$ & 0.21 & 0.16 & 0.14 & 0.78 & 0.21 & 0.00 & 1.00 \\
\hline category $=0)$ : & & & & & & 0.00 & \\
\hline 1 & 0.25 & 0.31 & -0.14 & 1.14 & 0.25 & & 1.00 \\
\hline 2 & 0.14 & 0.18 & -0.13 & 1.26 & 0.14 & & 1.00 \\
\hline$\geq 3$ & 0.11 & 0.16 & -0.17 & 1.39 & 0.11 & & 1.00 \\
\hline Unemployment rate in local area & 4.00 & 4.01 & -0.02 & 0.87 & 4.00 & 0.00 & 1.00 \\
\hline $\begin{array}{l}\text { Welfare generosity index } \\
\text { Maternal characteristics from birth } \\
\text { record data }\end{array}$ & 0.15 & 0.15 & 0.01 & 1.30 & 0.15 & 0.00 & 1.00 \\
\hline $\begin{array}{l}\text { Began prenatal care late in pregnancy } \\
\text { Inadequate weight gain during }\end{array}$ & 0.35 & 0.38 & -0.08 & 1.04 & 0.35 & 0.00 & 1.00 \\
\hline pregnancy & 0.20 & 0.21 & -0.02 & 1.03 & 0.20 & 0.00 & 1.00 \\
\hline Acute or chronic lung disease & 0.13 & 0.10 & 0.10 & 0.76 & 0.13 & 0.00 & 1.00 \\
\hline Anemia $(\mathrm{Hct}<30 / \mathrm{Hgb})$ & 0.14 & 0.15 & -0.06 & 1.11 & 0.14 & & 1.00 \\
\hline Cardiac disease & 0.03 & 0.04 & -0.09 & 1.50 & 0.03 & 0.00 & 1.00 \\
\hline
\end{tabular}


TABLE 2 (continued)

\begin{tabular}{|c|c|c|c|c|c|c|c|}
\hline \multirow[b]{2}{*}{ Baseline measure } & \multirow[b]{2}{*}{$\begin{array}{l}\text { Treated } \\
\text { mean }\end{array}$} & \multicolumn{3}{|c|}{ Unweighted } & \multicolumn{3}{|c|}{ Weighted } \\
\hline & & $\begin{array}{l}\text { Control } \\
\text { mean }\end{array}$ & $\begin{array}{l}\text { Std. } \\
\text { diff. }\end{array}$ & $\begin{array}{l}\text { Variance } \\
\text { Ratio }\end{array}$ & $\begin{array}{l}\text { Control } \\
\text { mean }\end{array}$ & $\begin{array}{l}\text { Std. } \\
\text { diff. }\end{array}$ & $\begin{array}{l}\text { Variance } \\
\text { Ratio }\end{array}$ \\
\hline Hypertension (preexisting) & 0.03 & 0.02 & 0.07 & 0.63 & 0.03 & 0.00 & 1.00 \\
\hline Pelvic inflammatory disease & 0.09 & 0.09 & 0.01 & 0.98 & 0.09 & 0.00 & 1.00 \\
\hline Renal disease & 0.12 & 0.10 & 0.07 & 0.84 & 0.12 & 0.00 & 1.00 \\
\hline Other preexisting condition & 0.50 & 0.36 & 0.28 & 0.92 & 0.50 & 0.00 & 1.00 \\
\hline Mother is obese & 0.16 & 0.21 & -0.15 & 1.25 & 0.16 & 0.00 & 1.00 \\
\hline Negative blood lab outcome & 0.52 & 0.37 & 0.30 & 0.94 & 0.52 & 0.00 & 1.00 \\
\hline Depression/other mental health problem & 0.12 & 0.06 & 0.19 & 0.51 & 0.12 & 0.00 & 1.00 \\
\hline Family dysfunction/instability & 0.07 & 0.02 & 0.20 & 0.30 & 0.07 & 0.00 & 1.00 \\
\hline Suspected parenting inadequacy & 0.10 & 0.03 & 0.22 & 0.35 & 0.10 & 0.00 & 1.00 \\
\hline Domestic violence/abuse in household & 0.05 & 0.03 & 0.06 & 0.74 & 0.05 & 0.00 & 1.00 \\
\hline Sexual abuse/molestation & 0.03 & 0.02 & 0.07 & 0.61 & 0.03 & 0.00 & 1.00 \\
\hline Any psychosocial risk factors reported & 0.80 & 0.89 & -0.22 & 0.62 & 0.80 & 0.00 & 1.00 \\
\hline Any substance use during pregnancy & 0.30 & 0.16 & 0.30 & 0.65 & 0.30 & 0.00 & 1.00 \\
\hline Existing mental health problems & 0.14 & 0.07 & 0.20 & 0.55 & 0.14 & 0.00 & 1.00 \\
\hline Any situational risks reported in chart & 0.89 & 0.92 & -0.09 & 0.77 & 0.89 & 0.00 & 1.00 \\
\hline Mother referred to special services & 0.49 & 0.29 & 0.38 & 0.83 & 0.48 & 0.00 & 1.00 \\
\hline $\begin{array}{l}\text { member with criminal justice system } \\
\text { Mother has inadequate financial }\end{array}$ & 0.04 & 0.01 & 0.14 & 0.34 & 0.04 & 0.00 & 1.00 \\
\hline resources & 0.05 & 0.05 & -0.01 & 1.02 & 0.05 & 0.00 & 1.00 \\
\hline Mother has physical disability & 0.03 & 0.01 & 0.11 & 0.32 & 0.03 & 0.00 & 1.00 \\
\hline Mother reports poor living conditions & 0.02 & 0.01 & 0.11 & 0.29 & 0.02 & 0.00 & 1.00 \\
\hline Pregnancy was unwanted & 0.02 & 0.01 & 0.02 & 0.82 & 0.02 & 0.00 & 1.00 \\
\hline
\end{tabular}

Note: Descriptive statistics are produced using the mother baseline city sample weights. Mother's earnings include zeros (those who do not work). Sample years for the baseline survey include 1998 to 2000.

${ }^{*}$ Absolute value of the standardized difference $>0.05 .{ }^{\wedge}$ Variance ratio $>2$ or $<0.5$. 
Table 3. Summary statistics of key variables by wave

\begin{tabular}{|c|c|c|c|c|c|}
\hline Variable & Wave 2 & Wave 3 & Wave 4 & Wave 5 & Wave 6 \\
\hline \multicolumn{6}{|l|}{ Labor supply } \\
\hline Mom worked last week (\%) & 47.8 & 53.5 & 59.6 & 59.7 & 72.4 \\
\hline Mom's hours worked last week ${ }^{a}$ & 35.5 & 37.0 & 34.8 & 35.6 & 36.9 \\
\hline Mom's earnings last week (in $2017 \$)^{b}$ & 296 & 435 & 392 & 499 & 678 \\
\hline Mom worked last year (\%) ${ }^{\mathrm{a}}$ & 64.0 & 70.2 & 73.2 & 73.8 & 80.2 \\
\hline Mom's hours worked last yearb & 1,262 & 1,587 & 1,487 & 1,537 & 1,784 \\
\hline Mom's earnings last year (in 2017 \$) & 27,118 & 34,714 & 31,875 & 35,988 & 41,156 \\
\hline \multicolumn{6}{|l|}{ Benefit receipt } \\
\hline Child receives SSI (\%) & 1.3 & 1.5 & 2.0 & 3.6 & N.A. \\
\hline Mom receives TANF (\%) & 17.1 & 13.9 & 13.9 & 10.5 & 9.3 \\
\hline Mom receives SNAP (\%) & 25.2 & 25.9 & 31.5 & 36.4 & 34.5 \\
\hline $\begin{array}{l}\text { Mom receives other type of public assistance } \\
(\%)\end{array}$ & 3.3 & 5.6 & 4.3 & 5.9 & 7.3 \\
\hline \multicolumn{6}{|l|}{ Household income and poverty } \\
\hline Total household income (in 2017 \$) & 41,078 & 45,814 & 48,034 & 62,066 & 70,256 \\
\hline Under poverty line (\%) & 38.8 & 35.9 & 41.2 & 33.2 & 27.1 \\
\hline Mother experienced financial distress (\%) & 43.9 & 66.0 & 59.2 & 47.0 & 37.5 \\
\hline Mom experienced depression last year (\%) & 11.9 & 14.1 & 8.5 & 10.1 & 9.3 \\
\hline Parents married or cohabitating (\%) & 71.4 & 67.0 & 60.5 & 56.4 & 46.9 \\
\hline Child disability (\%) & 2.2 & 3.1 & 21.9 & 23.4 & 37.0 \\
\hline Neurodevelopmental & 0.10 & 0.23 & 5.77 & 14.25 & 18.92 \\
\hline Motor & 0.33 & 1.43 & 0.91 & 0.59 & 2.93 \\
\hline Sensory & 0.07 & 0.37 & 0.82 & 0.79 & N.A. \\
\hline Heart & 0.18 & 0.05 & 1.76 & 1.97 & 2.30 \\
\hline Speech & N.A. & 0.12 & 13.88 & 10.58 & N.A. \\
\hline Age of child & 1.1 & 2.9 & 5.1 & 9.3 & 15.3 \\
\hline Number of observations & 3,282 & 3,176 & 3,127 & 2,689 & 2,734 \\
\hline Sample years & 1999-2001 & $2001-2003$ & 2003-2006 & 2007-2010 & 2014-2017 \\
\hline
\end{tabular}

Note: Descriptive statistics are produced using the analytic sample in each wave (defined as the sample for whom we have birth record data) and mother wave-specific city sample weights. Number of observations are unweighted. SSI = Supplemental Security Income; TANF = Temporary Aid to Needy Families; SNAP = Supplemental Nutrition Assistance Program.

${ }^{\text {aH}}$ Hours worked are conditional upon working. ${ }^{\mathrm{b}}$ Earnings include those with zero earnings. 


\section{RESULTS}

All results discussed in this section are estimated using weights constructed using entropy balancing. We use figures to illustrate the estimated average treated outcomes for treated families and counterfactual means for waves 2 to 6 (the estimated mean of the outcome if the treated families had not experienced a poor birth outcome). ${ }^{8}$ The difference between the two lines thus represents the ATT. To facilitate comparison with other studies and to reveal the extent to which entropy reweighting changes the coefficients, we also estimate models for each outcome using OLS and report the results in appendix tables A1 to A4.

We first examine the subsequent health trajectories of infants with poor neonatal health. This analysis also serves as a "first-stage" test. That is, if infants with poor neonatal health become children whose health is not significantly different from that of their counterparts, then we would not expect to see any differences in the other outcomes we examine.

Indeed, children who have poor neonatal health are significantly more likely to be classified as having a disability in subsequent years (Table 4; Figure 1, Panel A). In particular, treated children are more likely to develop neurodevelopmental disorders and are at heightened risk of developing motor and speech disorders (Table 4; Figure 1, Panels B to F). It is worth noting that even the counterfactual proportion of children who develop disabilities or chronic health conditions is high. Nonetheless, being born with a poor birth outcome is associated with a substantial increase in the likelihood of being diagnosed with a disability, but the increase diminishes in magnitude over time. When they are age 1, treated children are three times more likely to be diagnosed with any disability (6.7 percent versus 2.2 percent). By the time they are age 3 , treated children are more than twice as likely to be diagnosed with a disability (6.7 percent versus 3.1 percent). By the time they are age 5, the increased risk of being diagnosed with a disability for treated children falls to around 14 percent (24.9 percent versus 21.9 percent). Treated children are 30 percent more likely to be diagnosed with a disability in the fifth wave when they are 9 (30.3 percent versus 23.4 percent), and 20 percent more likely in the sixth wave, when they are 15 (44.4 percent versus 37.0 percent). One potential explanation for the diminished gap in the likelihood of diagnoses in later years is that children who had a poor birth outcome may be subject to more extensive follow-up care and monitoring in early childhood, whereas many disabilities for non-treated children may not be diagnosed until they enter school.

We then examine the consequences of having a child born in poor health on maternal labor supply and earnings (Table 5 and Figure 2). In Figure 2, we show that treated mothers on average have lower labor force participation rates and work fewer hours, but the statistical significance of the coefficients suggests that the impacts of poor neonatal health on maternal labor force activity may be larger at the extensive margin, at which treated mothers are more likely to withdraw from the labor force, especially in the third wave, when the child is 3 . Treated mothers also tend to work fewer hours last year (if working), especially in the earlier waves, when the child is young. This might be explained by the intensive time required to care for a young child who had a poor birth outcome. While the measures of labor market activity are somewhat noisy, the net impact on maternal earnings is qualitatively consistent, with the decline

\footnotetext{
${ }^{8} \mathrm{We}$ do not include wave 1 in the figures because, as noted previously, many outcomes we examine were not asked about in the baseline survey.
} 
in earnings being the largest in waves 2 and 5, when mothers are more likely to withdraw from the labor force.

\section{Table 4. Impact of poor neonatal health and subsequent child disability}

\begin{tabular}{lcccccc} 
& & \multicolumn{5}{c}{ Type of disability } \\
\cline { 3 - 6 } Wave & Any disability & $\begin{array}{c}\text { Neuro- } \\
\text { developmental }\end{array}$ & Motor & Sensory & Heart & Speech \\
2 & $0.045^{* *}$ & $0.002^{* *}$ & 0.011 & -0.000 & -0.001 & N.A. \\
& $(0.017)$ & $(0.001)$ & $(0.007)$ & $(0.002)$ & $(0.002)$ & 0.005 \\
3 & $0.035^{* *}$ & $0.010^{* *}$ & $0.012^{*}$ & 0.005 & 0.002 & $(0.003)$ \\
& $(0.017)$ & $(0.004)$ & $(0.007)$ & $(0.005)$ & $(0.002)$ & $0.041^{*}$ \\
4 & 0.030 & $0.048^{* *}$ & 0.007 & -0.001 & $0.021^{* *}$ & $(0.024)$ \\
& $(0.056)$ & $(0.019)$ & $(0.013)$ & $(0.005)$ & $(0.010)$ & $0.035^{* *}$ \\
& $0.069^{* *}$ & $0.067^{* *}$ & $0.017^{* *}$ & $0.006^{*}$ & -0.015 & $(0.016)$ \\
& $(0.027)$ & $(0.026)$ & $(0.006)$ & $(0.003)$ & $(0.013)$ & 0.006 \\
& $0.074^{* *}$ & $0.090^{*}$ & 0.006 & & 0.001 & $(0.004)$
\end{tabular}

Note: $\quad$ Each cell represents the weighted least squares estimate from a separate regression, using weights constructed through entropy balancing. Robust standard errors in parentheses are clustered by the national sampling unit. Sensory disorders include blindness and deafness. Motor disorders include problems with limbs and cerebral palsy. Neurodevelopmental disorders include developmental, autism, and attention deficit hyperactivity disorders. N.A. $=$ the referenced disability was not asked about in the survey wave.

${ }^{* / * * / * \star *}$ Statistically significant at the $.10 / .05 / .01$ level. 
Figure 1. Impact of poor neonatal health on subsequent child disability A. Any child disability

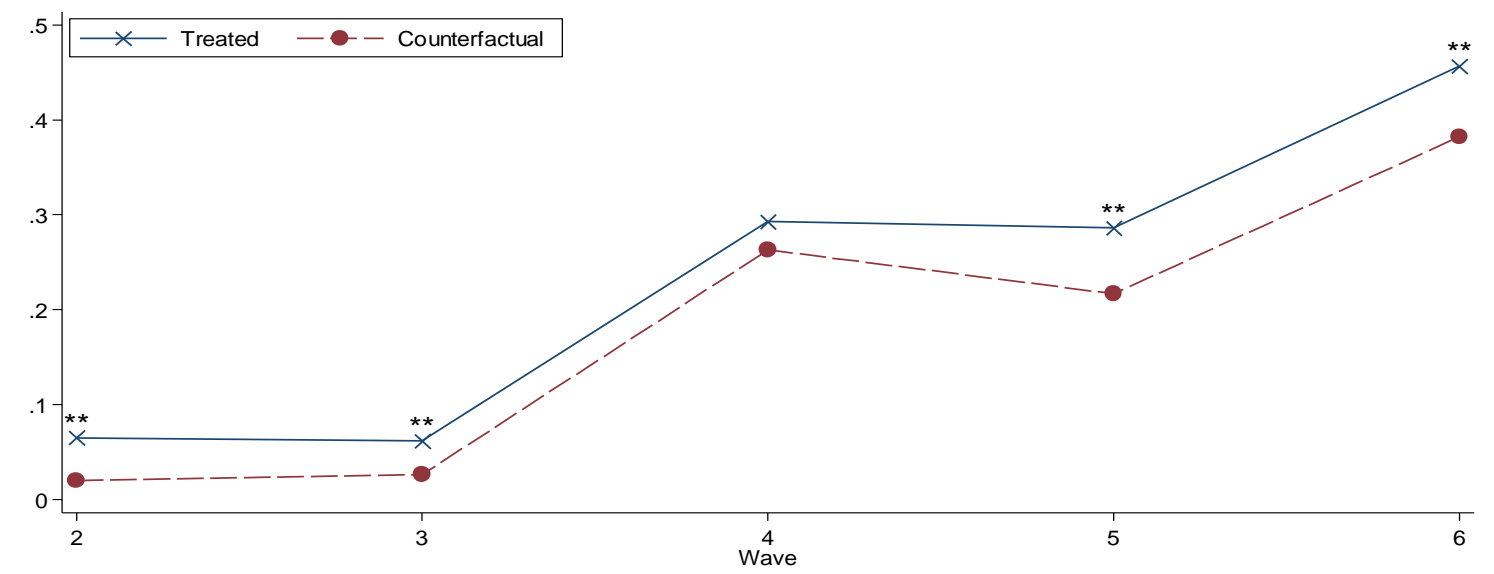

B. Neurodevelopmental disability

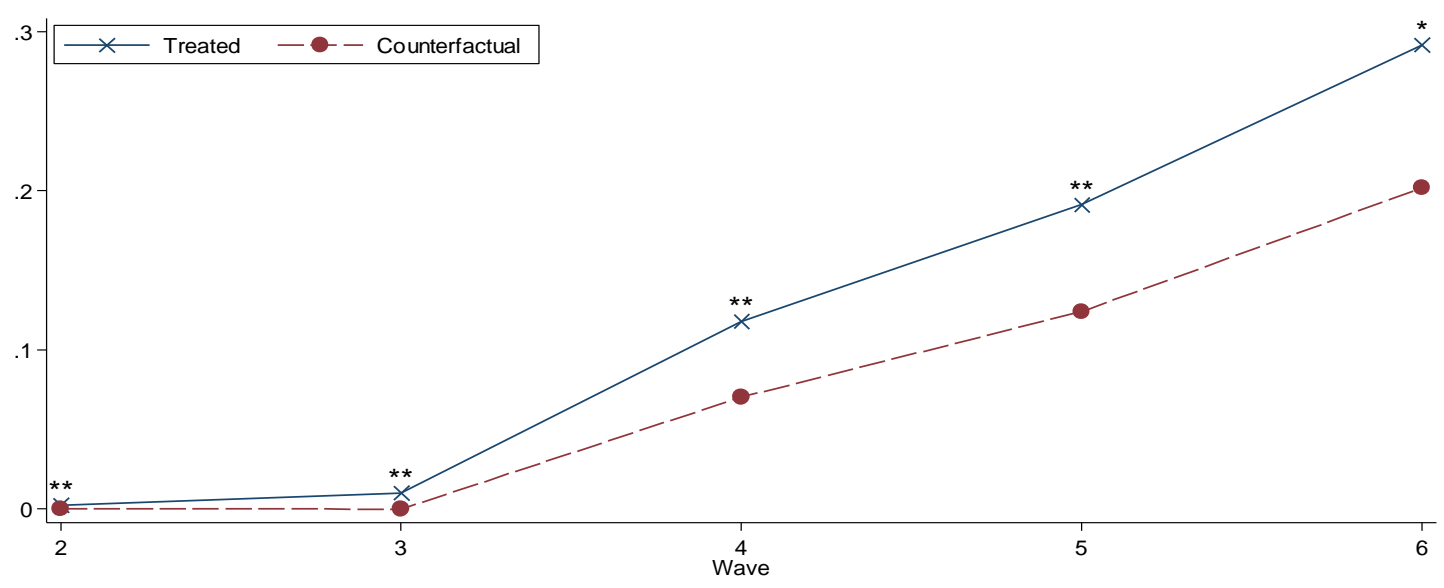

C. Motor disability

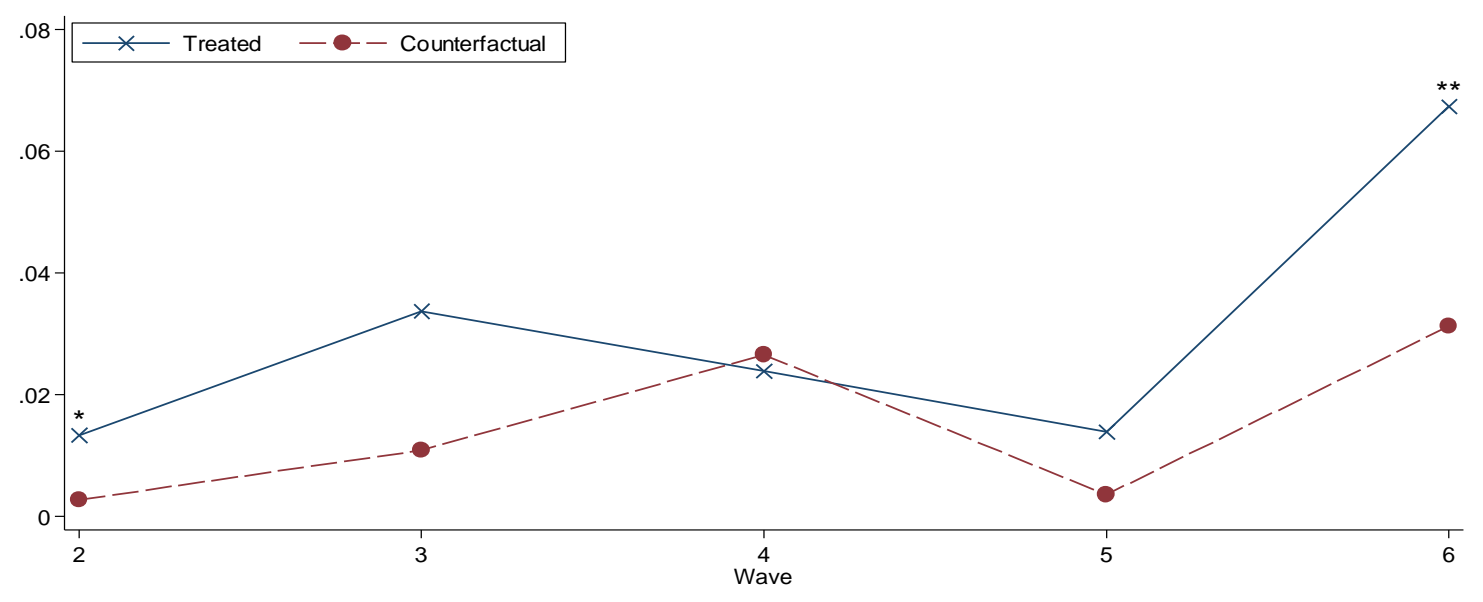


Figure 1 (continued)

\section{Sensory disability}

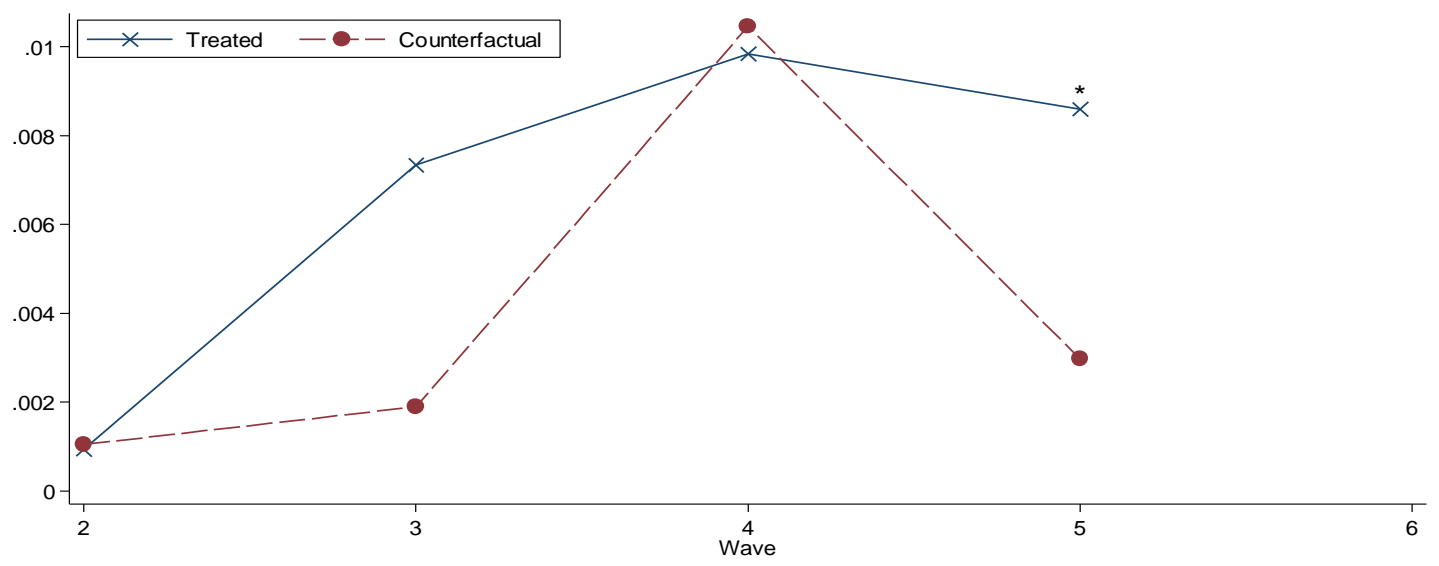

\section{E. Speech disorder}

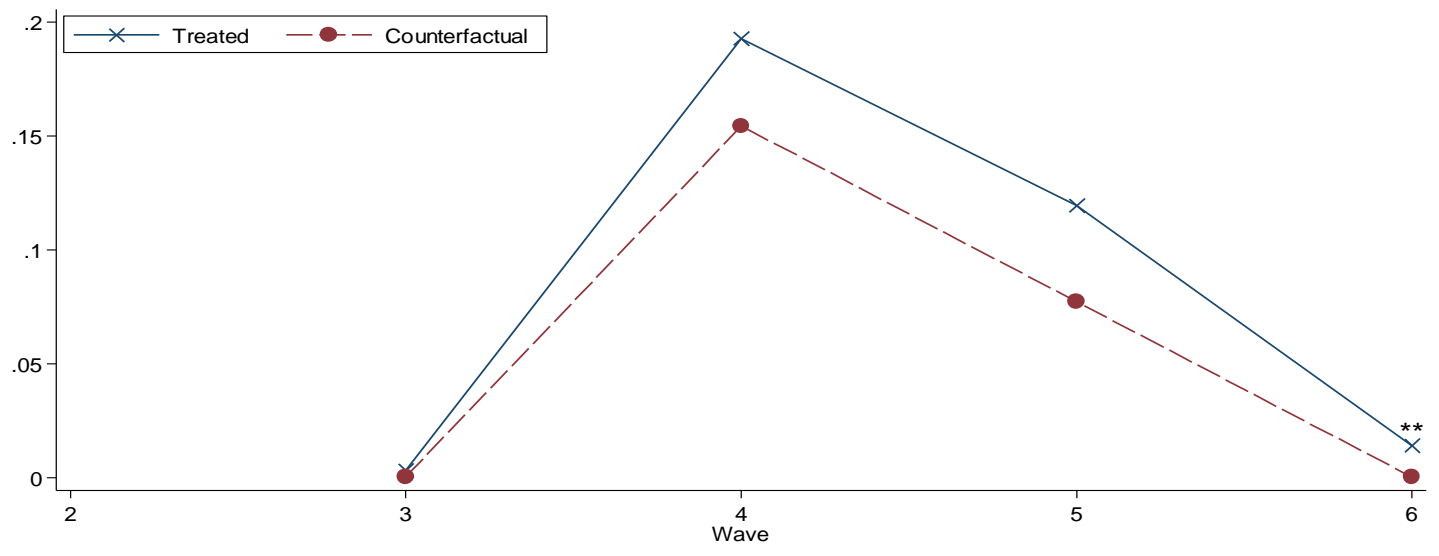

\section{F. Heart disorder}

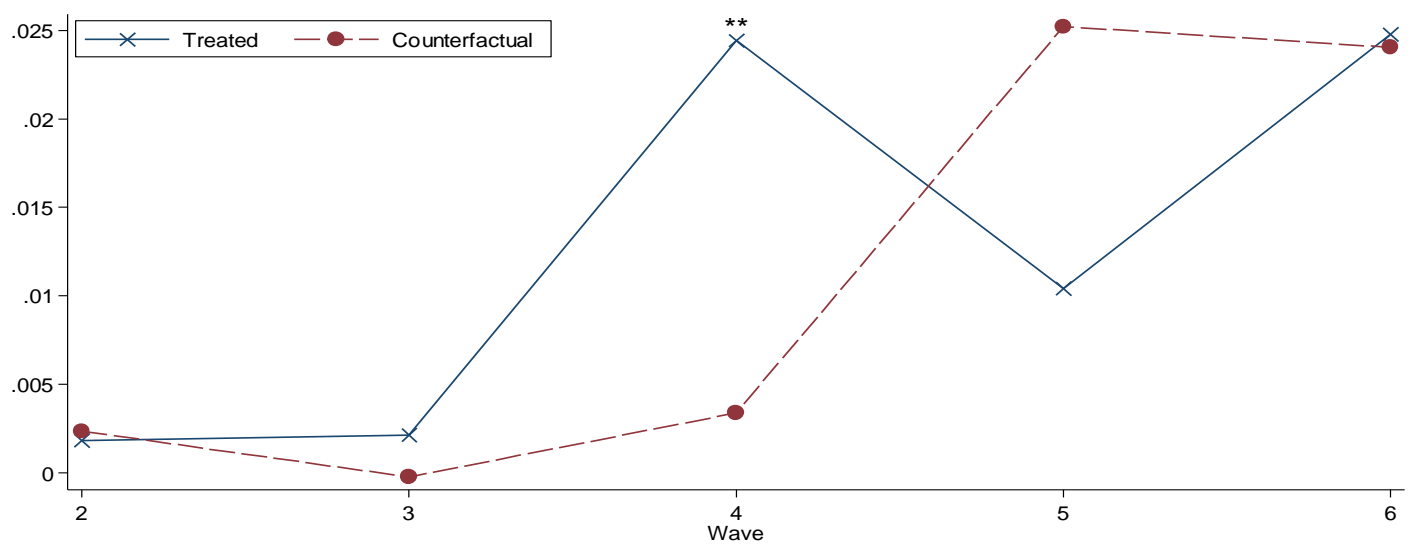

Note: Lines represent the regression-adjusted treated and counterfactual outcome means. Sensory disorders include blindness and deafness. Motor disorders include problems with limbs and cerebral palsy.

Neurodevelopmental disorders include developmental, autism, and attention-deficit/hyperactivity disorders.

${ }^{*} / * * * *$ Statistically significant at the $.10 / .05 / .01$ levels. 
Table 5. Impact of poor neonatal health on maternal labor market activity

\begin{tabular}{|c|c|c|c|c|c|c|}
\hline Wave & $\begin{array}{l}\text { Worked } \\
\text { last week }\end{array}$ & $\begin{array}{l}\text { Hours } \\
\text { worked } \\
\text { last week, } \\
\text { logged }\end{array}$ & $\begin{array}{l}\text { Earnings last } \\
\text { week, logged }\end{array}$ & $\begin{array}{l}\text { Worked last } \\
\text { year }\end{array}$ & $\begin{array}{l}\text { Hours } \\
\text { worked } \\
\text { last year } \\
\text { logged }\end{array}$ & $\begin{array}{l}\text { Earnings last } \\
\text { year, logged }\end{array}$ \\
\hline \multirow[t]{2}{*}{2} & 0.035 & 0.015 & 0.304 & 0.069 & -0.095 & 0.386 \\
\hline & $(0.062)$ & $(0.024)$ & $(0.333)$ & $(0.067)$ & $(0.063)$ & $(0.532)$ \\
\hline \multirow[t]{2}{*}{3} & $-0.083^{\star *}$ & -0.016 & $-0.365^{\star}$ & $-0.066^{* * *}$ & $-0.164^{* *}$ & -0.558 \\
\hline & $(0.031)$ & $(0.038)$ & $(0.202)$ & $(0.024)$ & $(0.067)$ & $(0.347)$ \\
\hline \multirow[t]{2}{*}{4} & 0.027 & -0.067 & 0.070 & 0.002 & 0.048 & 0.279 \\
\hline & $(0.041)$ & $(0.079)$ & $(0.183)$ & $(0.029)$ & $(0.097)$ & $(0.326)$ \\
\hline \multirow[t]{2}{*}{5} & $-0.090^{\star \star}$ & 0.032 & $-0.313^{*}$ & -0.055 & 0.168 & -0.281 \\
\hline & $(0.036)$ & $(0.052)$ & $(0.174)$ & $(0.033)$ & $(0.131)$ & $(0.319)$ \\
\hline \multirow[t]{2}{*}{6} & -0.013 & $-0.238^{* *}$ & 0.037 & -0.007 & $-0.217^{\star \star}$ & -0.218 \\
\hline & $(0.040)$ & $(0.105)$ & $(0.251)$ & $(0.034)$ & $(0.086)$ & $(0.234)$ \\
\hline
\end{tabular}

Note: Each cell represents the weighted least squares estimate from a separate regression, using weights constructed through entropy balancing. Robust standard errors in parentheses are clustered by the national sampling unit. Hours worked are conditional upon working. Earnings are augmented by 1 before logging and include those with zero earnings.

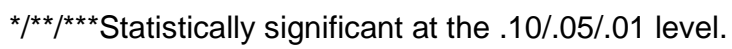


Figure 2. Impact of poor neonatal health on maternal labor market activity A. Mom worked last week

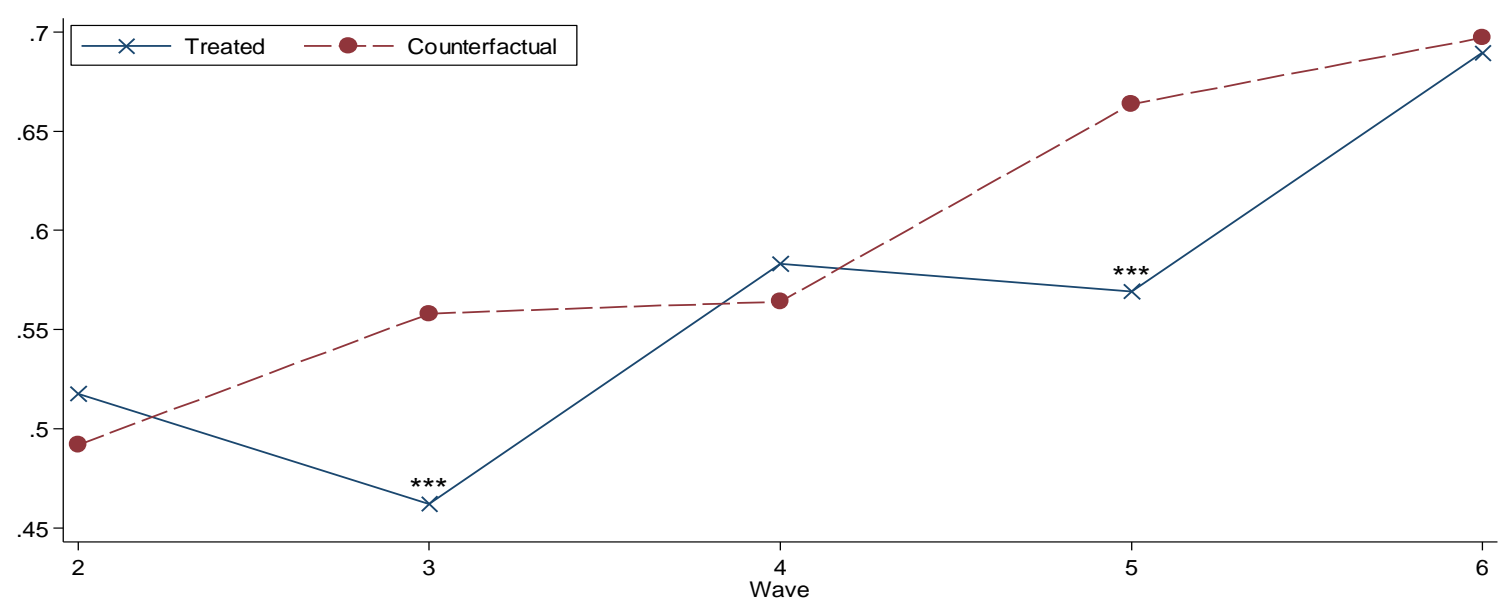

B. Mom's hours worked last week, logged

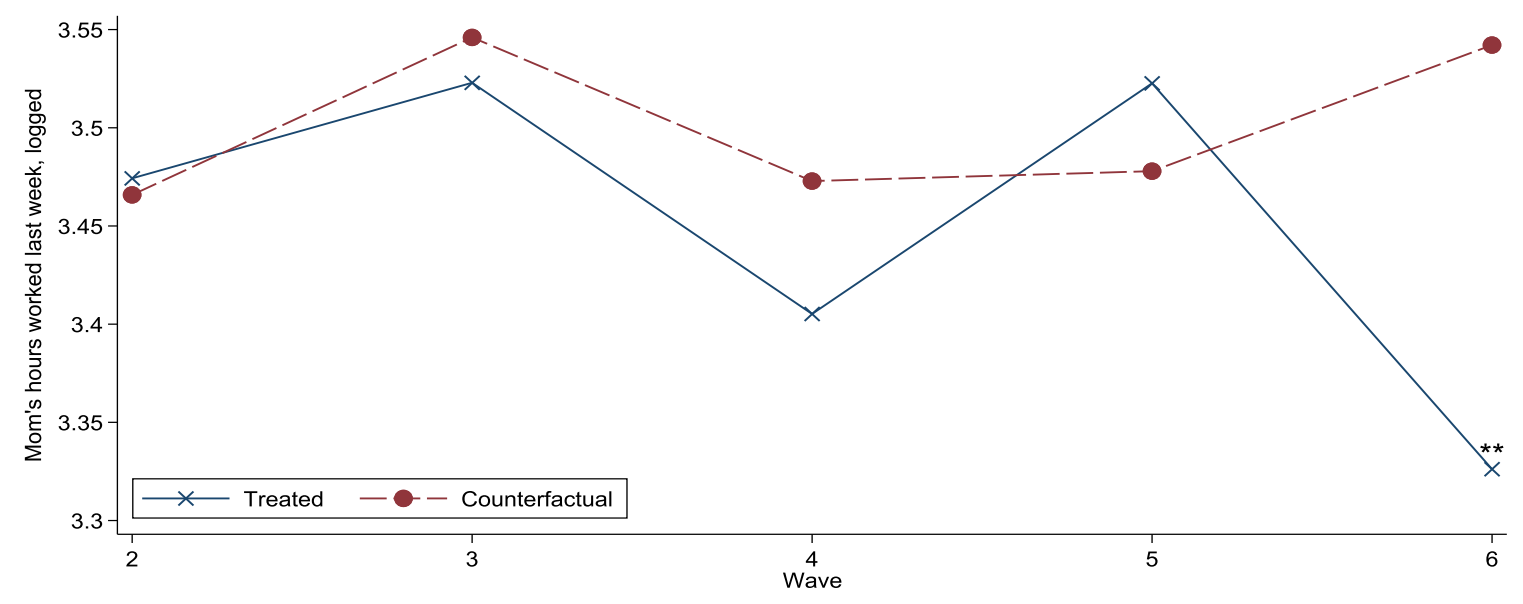

C. Mom's earnings last week, logged

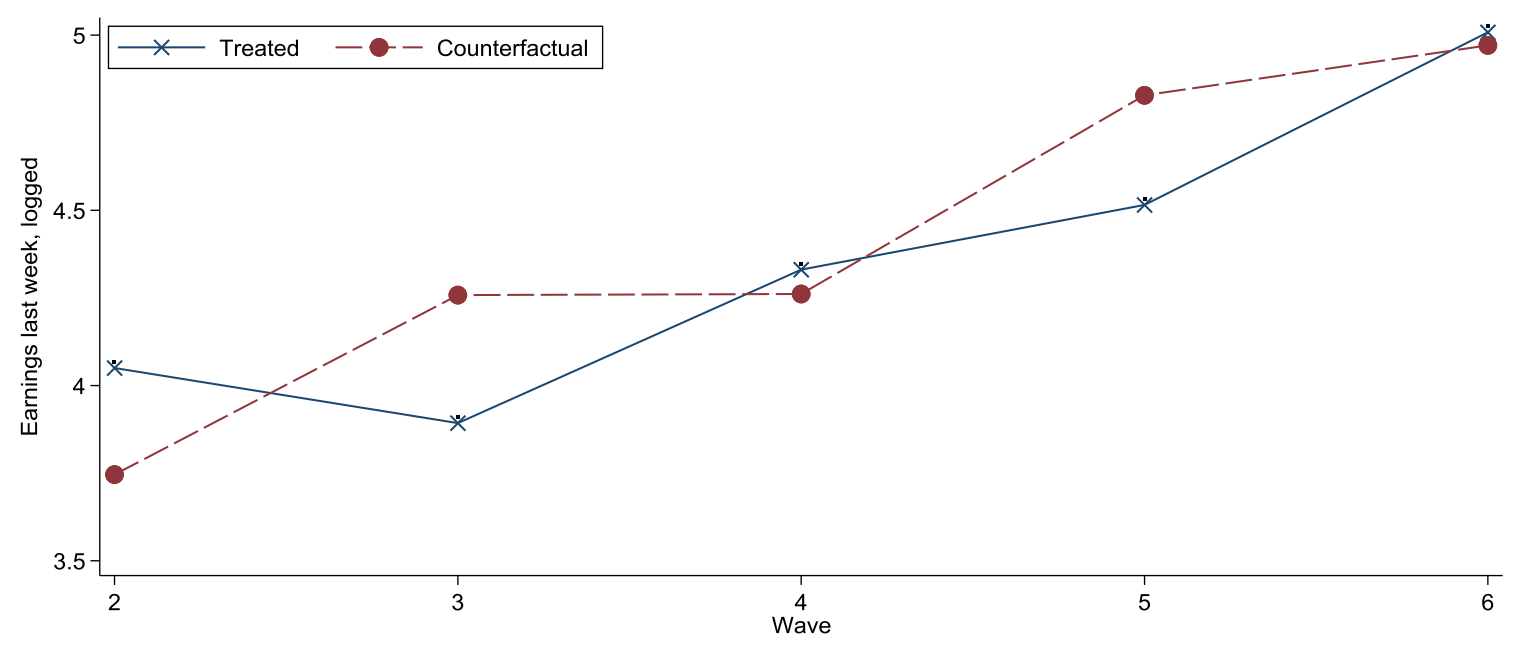


Figure 2 (continued)

D. Mom worked last year

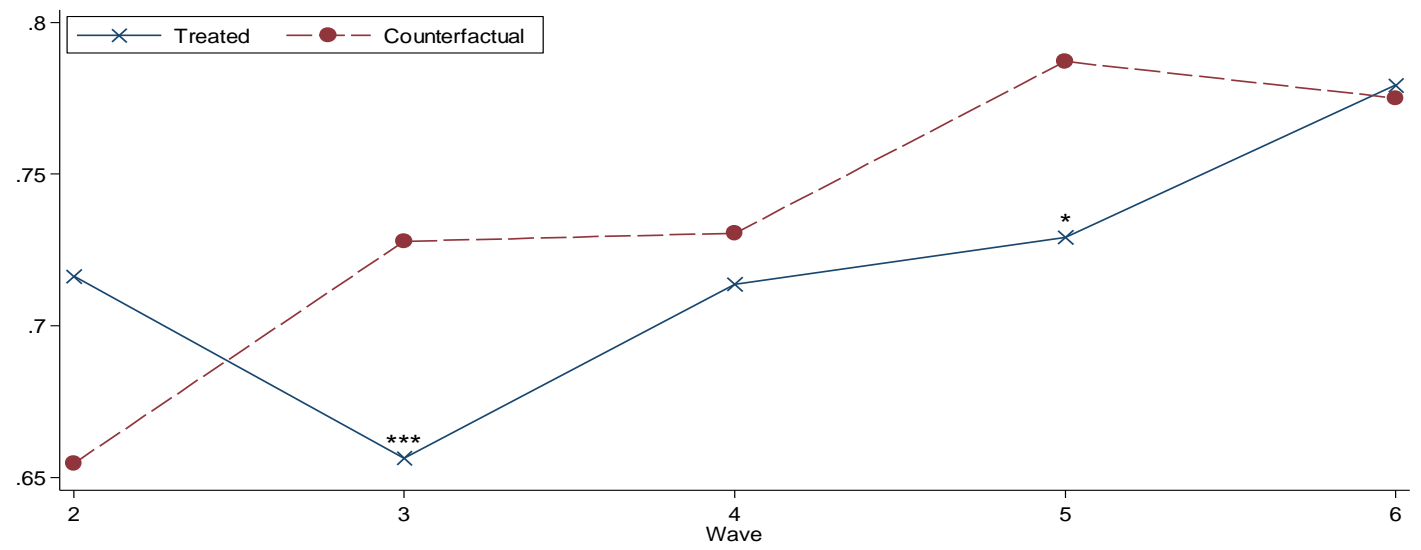

E. Mom's hours worked last year, logged

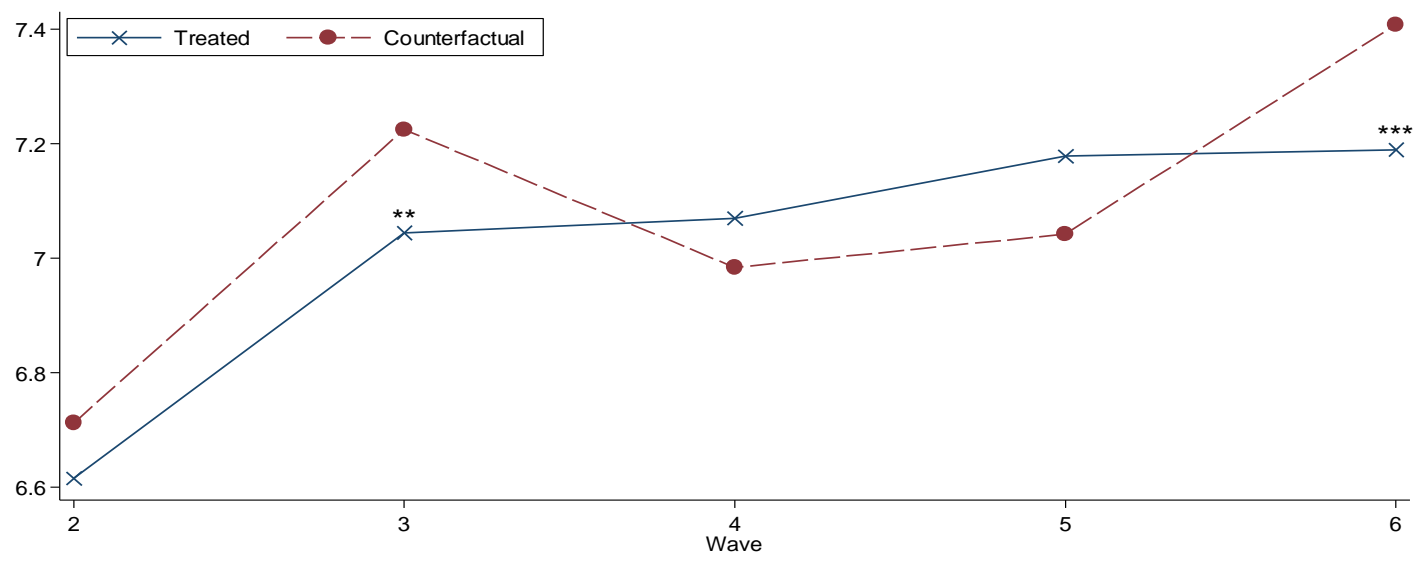

\section{F. Mom's earnings last year, logged}

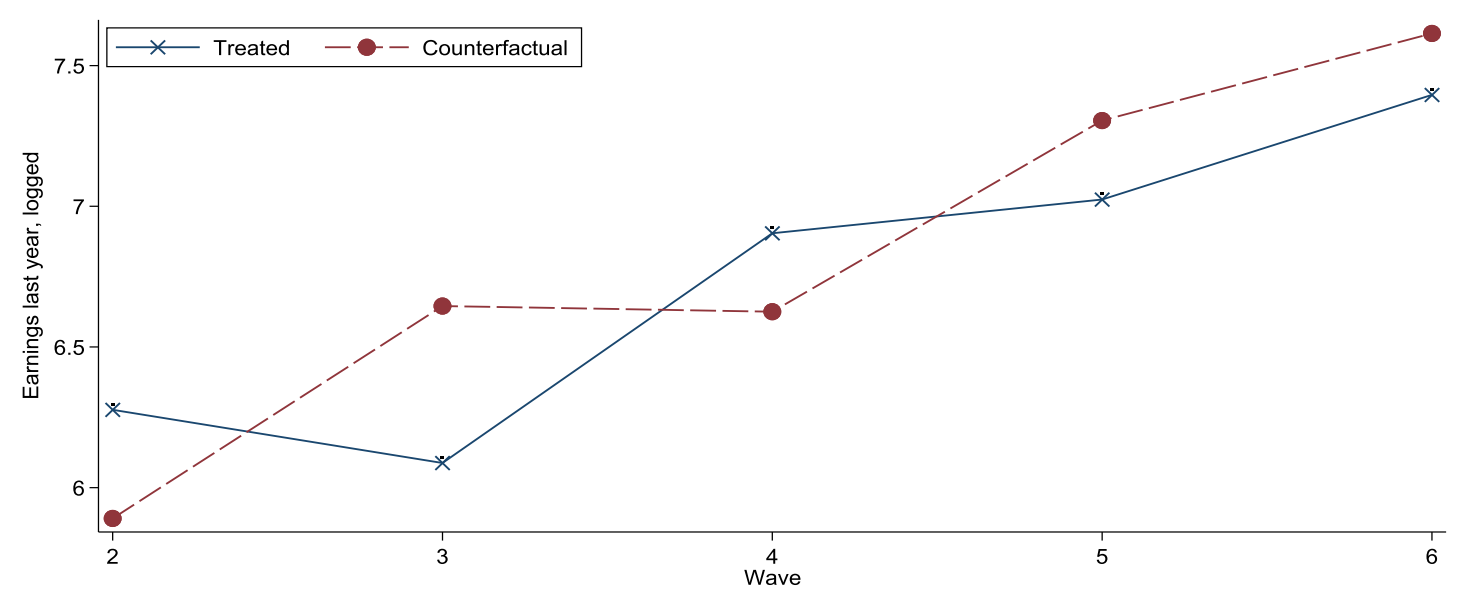

Note: Lines represent the regression-adjusted treated and counterfactual outcome means. Hours worked are conditional upon working. Earnings are augmented by 1 before logging and include those with zero earnings.

${ }^{*} / * * * * *$ Statistically significant at the $.10 / .05 / .01$ level. 
We find that children who had poor neonatal health are much more likely to receive child SSI (Table 6; Figure 3). Treated children are almost four times as likely to receive SSI by the time they are 1, relative to those who did not have a poor birth outcome (4.9 percent versus 1.3 percent). Treated children are close to five times as likely to receive SSI by the time they are 3 in wave 3 ( 7.1 percent versus 1.5 percent), close to three times as likely by the time they are 5 (5.6 percent versus 2.0 percent), and close to twice as likely by the time they are 9 (6.4 percent versus 3.6 percent). Treated mothers also have higher mean likelihoods of benefit receipt from SNAP and TANF relative to if they had not been treated, but not from other forms of public assistance.

We do not find any significant effects of poor neonatal health on household income (Table 7; Figure 4, panel A). Similarly, we do not find any statistically significant differences in the likelihood of household poverty among treated families, except in wave 6 (Table 7; Figures 4, panel B).

Finally, we examine two additional indicators of household well-being: maternal mental health and parental relationship status. Treated mothers do not have significantly different likelihoods of experiencing depression in subsequent waves, relative to what they otherwise would have experienced, except in wave 6 (Table 7; Figure 4, Panel C). However, our estimates indicate that poor neonatal health negatively affects the likelihood of parents being married or cohabiting in subsequent waves, with the magnitude of the effect growing over time. (Table 7; Figure 4, Panel D).

Table 6. Impact of poor neonatal health on benefit receipt

\begin{tabular}{lllll} 
Wave & \multicolumn{1}{c}{ Child SSI } & \multicolumn{2}{c}{ SNAP } & \multicolumn{1}{c}{$\begin{array}{c}\text { TANF } \\
\text { Other public } \\
\text { assistance }\end{array}$} \\
2 & $0.036^{* *}$ & 0.016 & 0.013 & 0.017 \\
& $(0.016)$ & $(0.022)$ & $(0.028)$ & $(0.011)$ \\
3 & $0.056^{* * *}$ & 0.067 & $0.036^{*}$ & -0.007 \\
& $(0.015)$ & $(0.052)$ & $(0.019)$ & $(0.016)$ \\
& $0.036^{* *}$ & $0.067^{* *}$ & $0.075^{* * *}$ & -0.006 \\
& $(0.013)$ & $(0.029)$ & $(0.024)$ & $(0.028)$ \\
& $0.028^{* *}$ & 0.049 & 0.005 & 0.003 \\
& $(0.013)$ & $(0.033)$ & $(0.053)$ & $(0.011)$ \\
& N.A. & $0.061^{* *}$ & 0.007 & -0.020 \\
& & $(0.029)$ & $(0.023)$ & $(0.014)$ \\
\hline
\end{tabular}

Note: Each cell represents the weighted least squares estimate from a separate regression, using weights constructed through entropy balancing. Robust standard errors in parentheses are clustered by the national sampling unit. SSI = Supplemental Security Income; SNAP = Supplemental Nutrition Assistance Program; TANF = Temporary Assistance for Needy Families; N.A. = not available because the outcome was not asked about in the survey wave.

${ }^{* / * * / * * *}$ Statistically significant at the $.10 / .05 / .01$ level. 
Figure 3. Impact of poor neonatal health on benefit receipt

\section{A. Child SSI receipt}

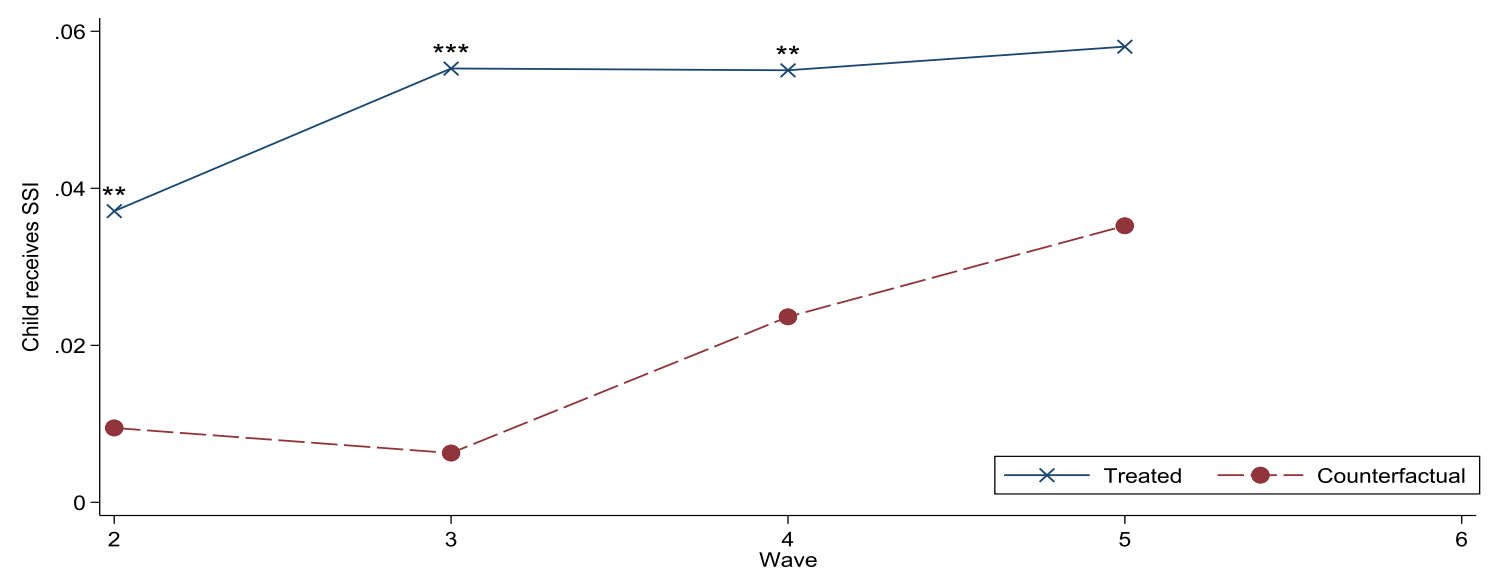

\section{B. Mom's SNAP receipt}

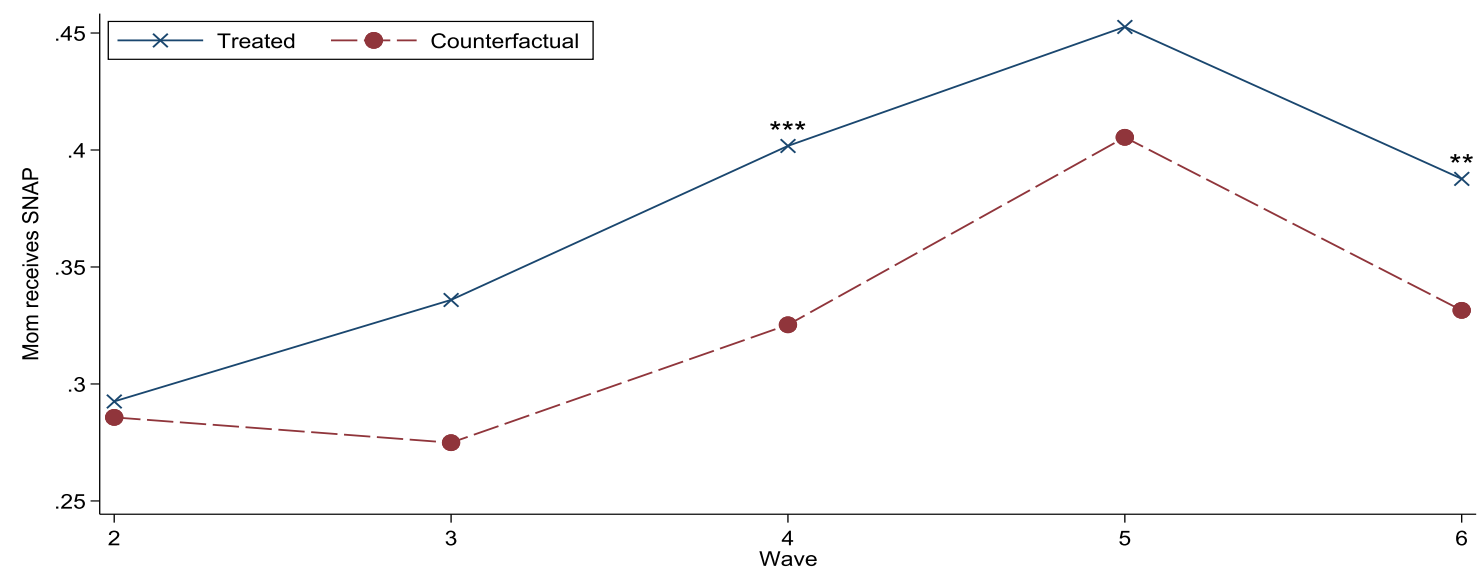

C. Mom's TANF receipt

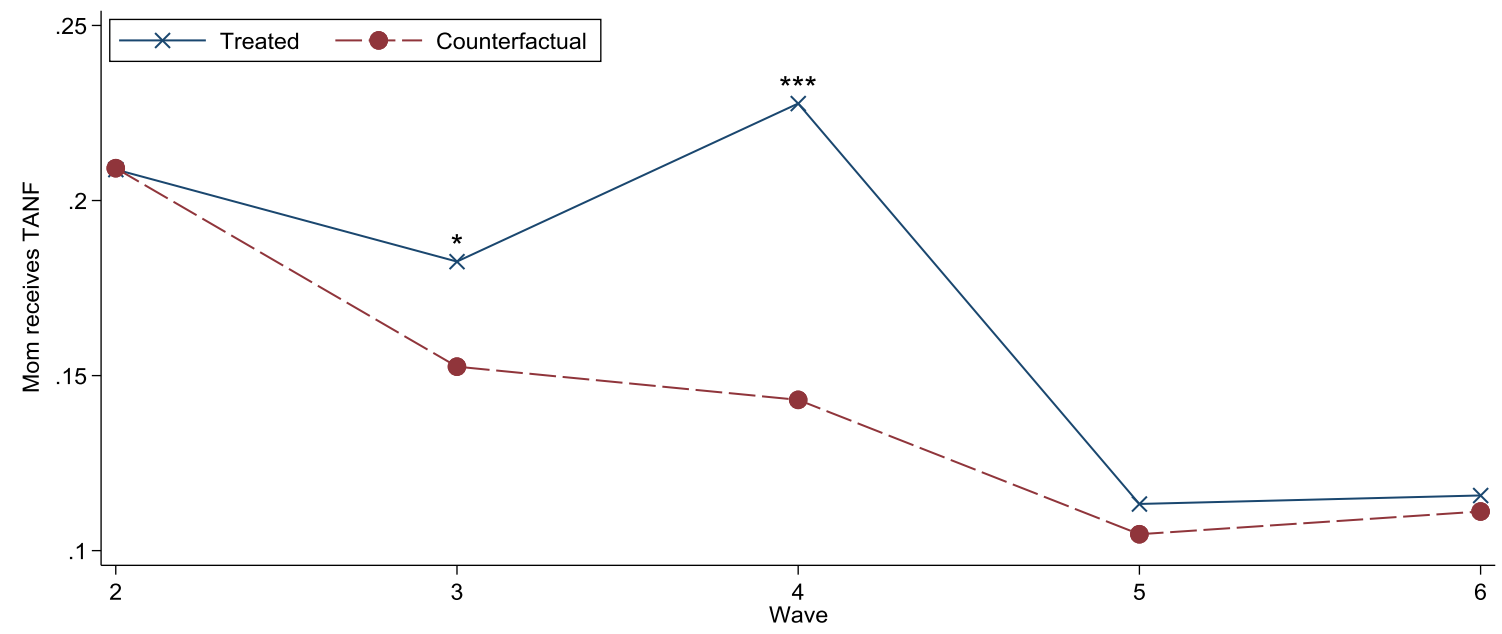


Figure 3 (continued)

D. Mom's receipt of other public assistance program benefits

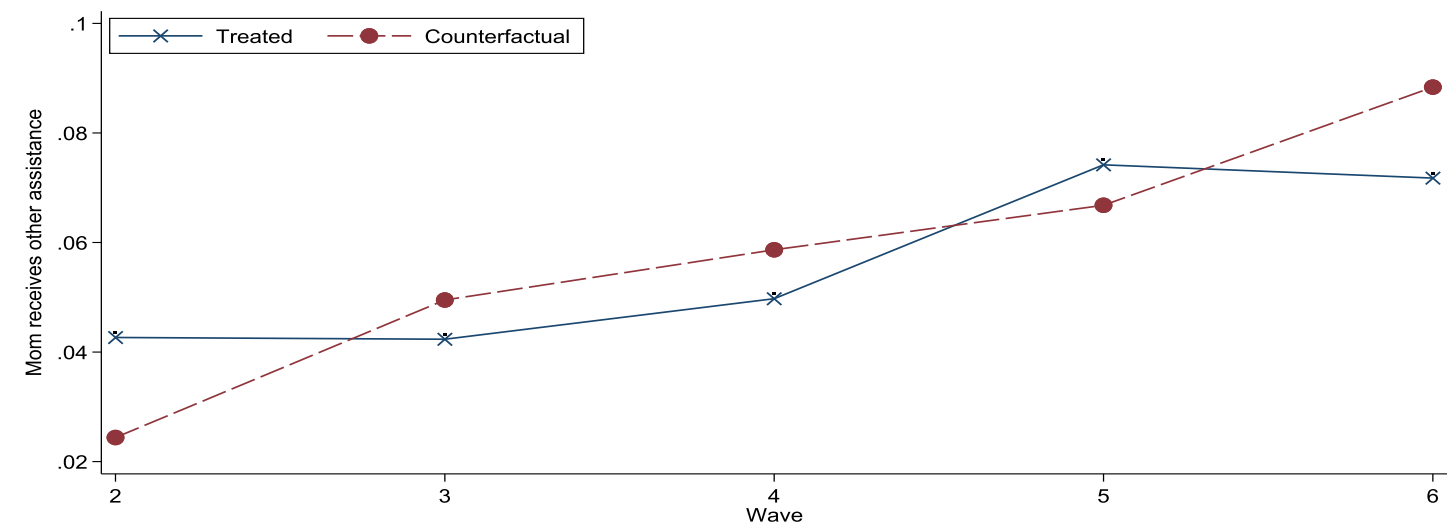

Note: Lines represent the regression-adjusted treated and counterfactual outcome means. Hours worked are conditional upon working. Information on child SSI receipt was not available in wave 6.

${ }^{*} / * * * * *$ Statistically significant at the $.10 / .05 / .01$ level.

\section{Table 7. Impact of poor neonatal health on household well-being}

\begin{tabular}{lcccc} 
Wave & $\begin{array}{c}\text { Household income, } \\
\text { logged }\end{array}$ & Household poverty & $\begin{array}{c}\text { Mother experienced } \\
\text { depression }\end{array}$ & $\begin{array}{c}\text { Parents married or } \\
\text { cohabitating }\end{array}$ \\
2 & -0.025 & 0.018 & -0.009 & $-0.041^{* * *}$ \\
3 & $(0.155)$ & $(0.044)$ & $(0.021)$ & $(0.012)$ \\
& -0.055 & 0.039 & 0.017 & $-0.047^{*}$ \\
4 & $(0.177)$ & $(0.047)$ & $(0.022)$ & $(0.023)$ \\
& 0.023 & -0.035 & -0.006 & -0.037 \\
5 & $(0.107)$ & $(0.074)$ & $(0.018)$ & $(0.042)$ \\
& -0.068 & 0.031 & 0.001 & $-0.071^{* *}$ \\
6 & $(0.177)$ & $(0.044)$ & $(0.020)$ & $(0.030)$ \\
& -0.049 & $0.089^{* * *}$ & $0.023^{*}$ & -0.075 \\
& $(0.115)$ & $(0.022)$ & $(0.013)$ & $(0.047)$ \\
\hline
\end{tabular}

Note: $\quad$ Each cell represents the weighted least squares estimate from a separate regression, using weights constructed through entropy balancing. Robust standard errors in parentheses are clustered by the national sampling unit. 
Figure 4. Impact of poor neonatal health on household well-being A. Household income, logged

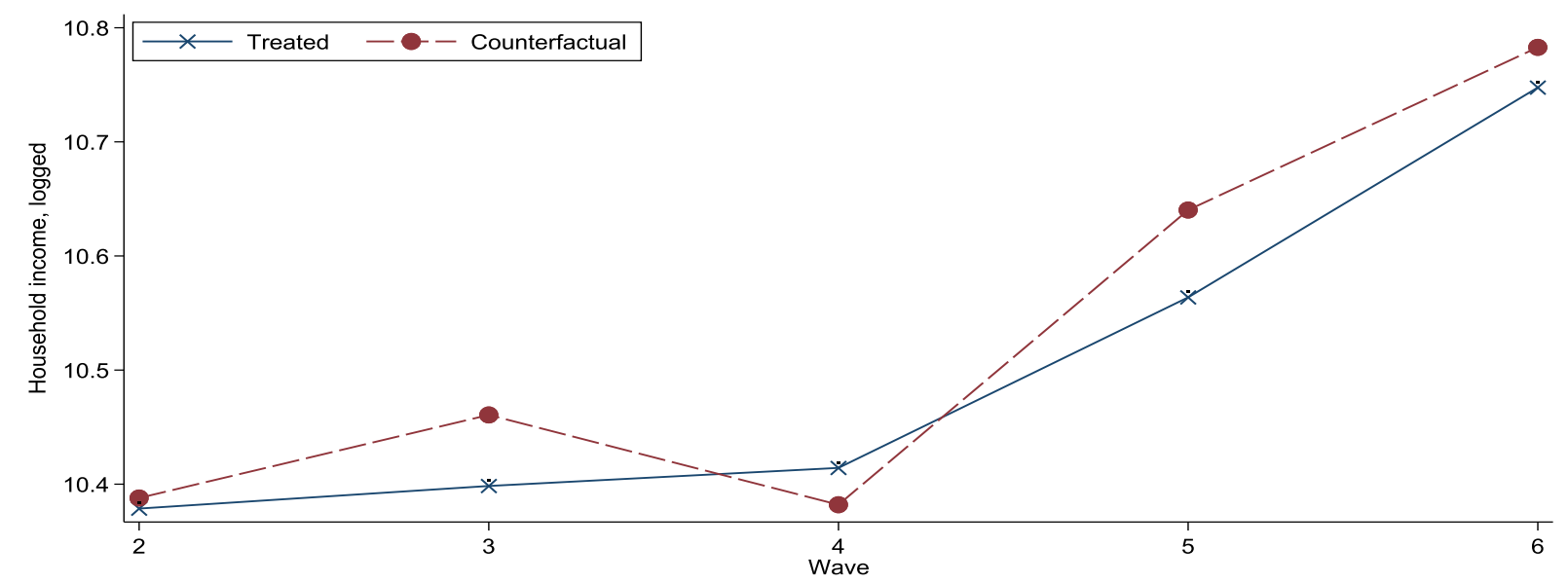

B. Poverty

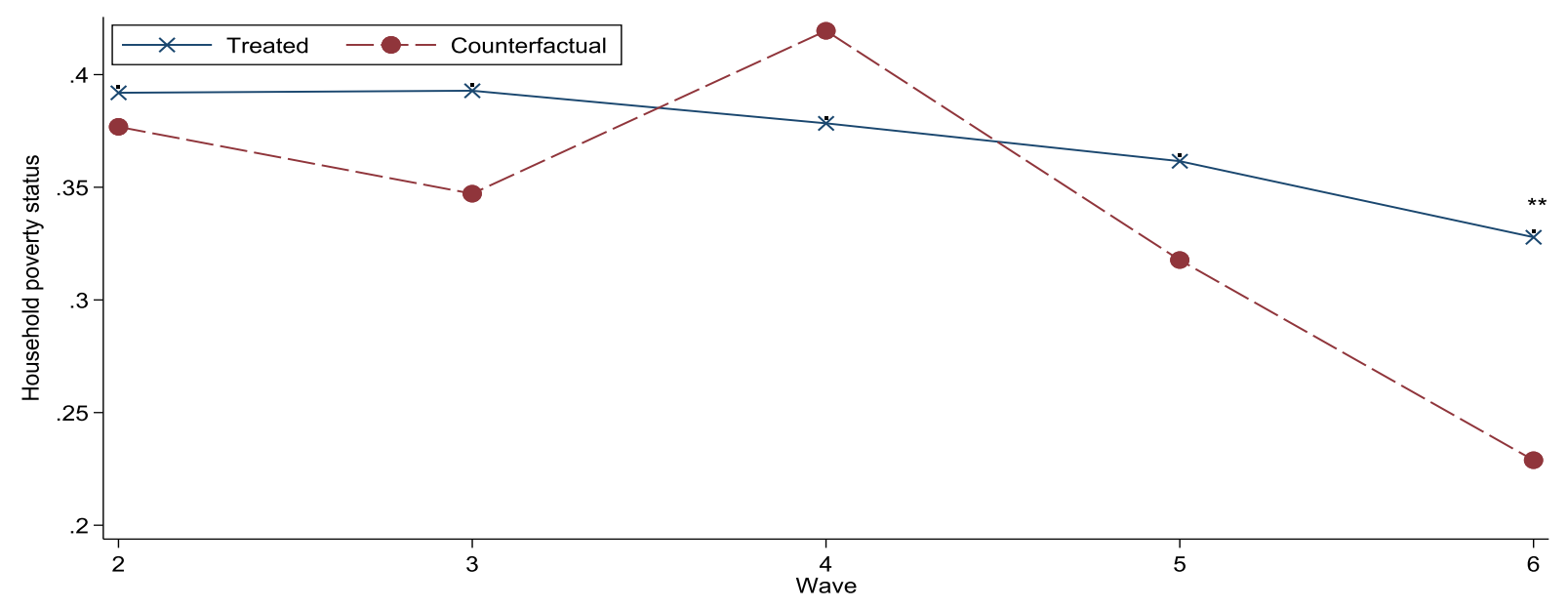

C. Mother experienced depression last year

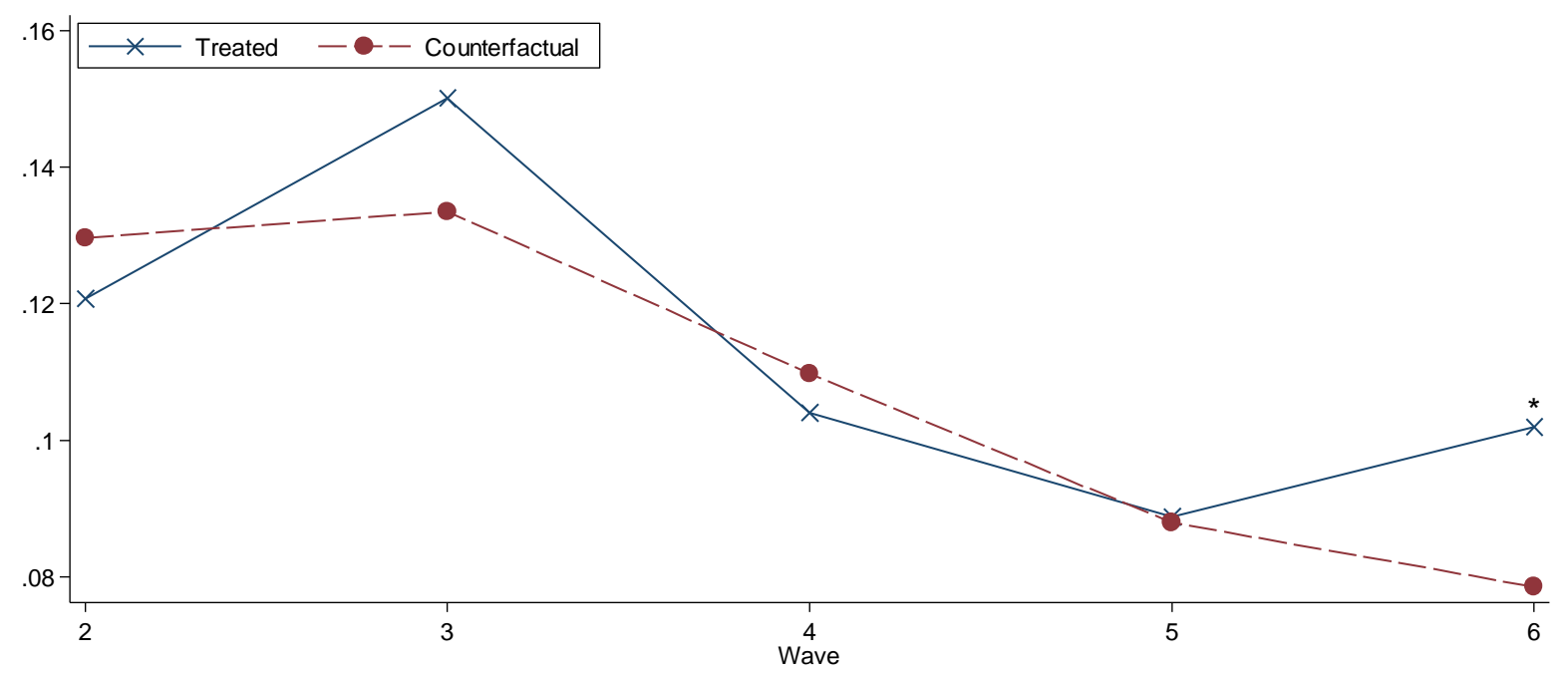


Figure 4 (continued)

\section{Parents married or cohabiting}

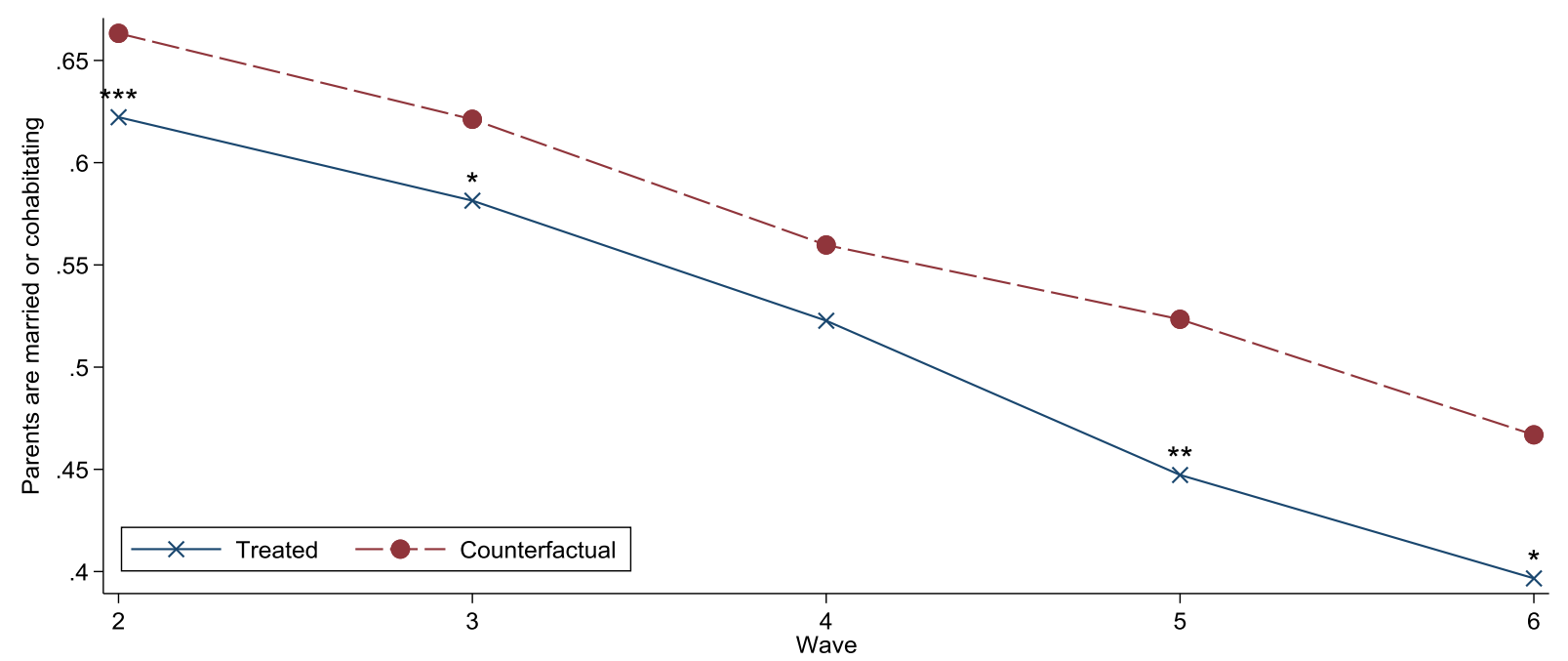

Note: Lines represent the regression-adjusted treated and counterfactual outcome means.

${ }^{*} / * * * * *$ Statistically significant at the $.10 / .05 / .01$ level.

The results from the OLS models are qualitatively consistent with the main results obtained with the entropy reweighting scheme. We present such results in the Appendix (tables A1 to A4), estimated first without any controls to represent raw differences between treated and untreated families, and then controlling for the same set of baseline covariates used in the entropy reweighted analysis (as well as hospital and state dummies). In general, raw differences are larger between treated and non-treated groups, which likely reflects preexisting differences in other confounders. Once we control for potential confounders, the estimates become much closer to those reported in the main tables. The magnitude of the estimates is generally larger in the OLS analyses, which suggests that OLS estimates — even when controlling for covariates - are upward biased. This analysis highlights both the need to control for baseline characteristics and the strength of entropy balancing to reduce the high dimensionality of a large set of baseline measures while ensuring covariate balance. 


\section{SENSITIVITY ANALYSES}

We conduct two exercises to examine how results vary with alternative definitions of poor neonatal health. First, we define it using only low birth weight (under 2,500 grams) and preterm birth ( $<37$ weeks), a commonly used definition of a poor birth outcome in the medical literature. Results are mostly similar when we use this definition, but there are several notable differences. First, the likelihood of being diagnosed with a child disability is higher when compared to the main results, which suggests that low birth weight and preterm births are stronger predictors of child disability. Second, treated mothers appear to increase labor force participation at both the intensive and the extensive margin in wave 2, when the child is 1 . It is possible that low birth weight and preterm birth are conditions that impose heavier financial relative to time burdens, driving mothers to work more. We do not have sufficient sample size to delve into a detailed subgroup analysis in this paper, and so we leave examining the heterogeneous effects by different birth conditions as a future research topic.

Second, we define poor neonatal health using only birth conditions that are considered not to be directly caused by maternal prenatal behavior. The coding of infants' abnormal health conditions was conducted by an outside pediatric consultant (appointed by the Fragile Families Study) who determined, from the birth record data and one-year maternal reports of child disability, how likely it was that the mother's prenatal behavior caused the condition. ${ }^{9}$ The motivation behind this sensitivity test is that even though we employ entropy reweighting, we might not have accounted sufficiently for omitted variable bias caused by unobserved differences when considering all abnormal birth conditions. By using only conditions that are plausibly exogenous, we may be better able to identify the causal effects of poor neonatal health. When we code poor neonatal health using only these conditions and exclude the sample of infants whose abnormal birth conditions were coded as likely to be caused by maternal behavior, the weighted estimates remain qualitatively similar for most dependent variables (Table 8, Panel B). ${ }^{10}$ In particular, the estimated effects on SSI receipt and child disability remain very similar. However, the effects on poverty and household income become more pronounced. Treated households are now more likely to have lower income and to be in poverty than if they had not been treated. This suggests that the effects on household economic well-being may be even more severe than we found in the main analysis. Because it is difficult to determine whether these birth conditions are truly random, we treat this exercise as a sensitivity test, while acknowledging that the estimates from the main analysis could be a lower bound.

\footnotetext{
${ }^{9}$ It should be noted that the consulting pediatrician coded most of the conditions as unlikely to be caused by maternal prenatal behavior. The mean of poor neonatal health coded in this way is 0.18 , which is only slightly lower than the mean of our main definition of poor neonatal health, which is 0.20 . More information about how the conditions were coded can be found at https://fragilefamilies.princeton.edu/restricted/medrecs.

${ }^{10}$ Results using OLS are also similar and are available upon request.
} 
Table 8. Sensitivity analyses: using different definitions of poor neonatal health

\begin{tabular}{|c|c|c|c|c|c|c|c|c|c|c|c|}
\hline Wave & $\begin{array}{c}\text { Mom } \\
\text { worked } \\
\text { last week }\end{array}$ & $\begin{array}{l}\text { Mom's } \\
\text { hours } \\
\text { worked } \\
\text { last week, } \\
\text { logged }\end{array}$ & $\begin{array}{l}\text { Mom's } \\
\text { earnings } \\
\text { last week, } \\
\text { logged }\end{array}$ & $\begin{array}{l}\text { Mom } \\
\text { worked } \\
\text { last year }\end{array}$ & $\begin{array}{l}\text { Mom's } \\
\text { hours } \\
\text { worked } \\
\text { last year, } \\
\text { logged }\end{array}$ & $\begin{array}{l}\text { Mom's } \\
\text { earnings } \\
\text { last year, } \\
\text { logged }\end{array}$ & $\begin{array}{c}\text { Child SSI } \\
\text { receipt }\end{array}$ & $\begin{array}{l}\text { Household } \\
\text { income, } \\
\text { logged }\end{array}$ & $\begin{array}{c}\text { Poverty } \\
\text { status }\end{array}$ & $\begin{array}{l}\text { Child } \\
\text { disability }\end{array}$ & $\begin{array}{l}\text { Parents } \\
\text { married } \\
\text { or } \\
\text { cohabitat } \\
\text { ing }\end{array}$ \\
\hline \multirow{2}{*}{$\begin{array}{l}\text { A } \\
2\end{array}$} & \multicolumn{11}{|c|}{ Defining poor neonatal health using by low birth weight and preterm birth only $($ mean $=0.15)$} \\
\hline & $\begin{array}{c}0.035 \\
(0.041)\end{array}$ & $\begin{array}{l}0.100^{\star *} \\
(0.044)\end{array}$ & $\begin{array}{c}0.207 \\
(0.181)\end{array}$ & $\begin{array}{c}0.049^{*} \\
(0.027)\end{array}$ & $\begin{array}{c}0.031 \\
(0.072)\end{array}$ & $\begin{array}{c}0.343 \\
(0.286)\end{array}$ & $\begin{array}{l}0.020^{* *} \\
(0.009)\end{array}$ & $\begin{array}{l}-0.056 \\
(0.096)\end{array}$ & $\begin{array}{c}0.021 \\
(0.029)\end{array}$ & $\begin{array}{l}0.047^{\star * *} \\
(0.016)\end{array}$ & $\begin{array}{l}-0.035^{*} \\
(0.020)\end{array}$ \\
\hline 3 & $\begin{array}{l}-0.023 \\
(0.035)\end{array}$ & $\begin{array}{l}-0.024 \\
(0.038)\end{array}$ & $\begin{array}{l}-0.313 \\
(0.310)\end{array}$ & $\begin{array}{l}-0.032 \\
(0.032)\end{array}$ & $\begin{array}{l}-0.163^{\star *} \\
(0.072)\end{array}$ & $\begin{array}{l}-0.522 \\
(0.484)\end{array}$ & $\begin{array}{l}0.036^{* *} \\
(0.017)\end{array}$ & $\begin{array}{l}-0.080 \\
(0.154)\end{array}$ & $\begin{array}{c}0.041 \\
(0.034)\end{array}$ & $\begin{array}{c}0.042 \\
(0.027)\end{array}$ & $\begin{array}{l}-0.094^{* *} \\
(0.039)\end{array}$ \\
\hline 4 & $\begin{array}{c}0.032 \\
(0.053)\end{array}$ & $\begin{array}{l}0.103^{\star *} \\
(0.049)\end{array}$ & $\begin{array}{c}0.005 \\
(0.203)\end{array}$ & $\begin{array}{l}-0.026 \\
(0.032)\end{array}$ & $\begin{array}{l}0.198^{\star *} \\
(0.087)\end{array}$ & $\begin{array}{c}0.137 \\
(0.424)\end{array}$ & $\begin{array}{c}0.035^{*} \\
(0.018)\end{array}$ & $\begin{array}{l}-0.019 \\
(0.042)\end{array}$ & $\begin{array}{l}-0.037 \\
(0.034)\end{array}$ & $\begin{array}{c}0.103^{* *} \\
(0.045)\end{array}$ & $\begin{array}{l}-0.098^{\star *} \\
(0.045)\end{array}$ \\
\hline 5 & $\begin{array}{l}-0.016 \\
(0.042)\end{array}$ & $\begin{array}{c}0.066 \\
(0.075)\end{array}$ & $\begin{array}{l}-0.463 \\
(0.303)\end{array}$ & $\begin{array}{l}-0.063 \\
(0.053)\end{array}$ & $\begin{array}{c}0.250 \\
(0.169)\end{array}$ & $\begin{array}{l}-0.729 \\
(0.463)\end{array}$ & $\begin{array}{c}0.037 \\
(0.027)\end{array}$ & $\begin{array}{l}-0.119 \\
(0.159)\end{array}$ & $\begin{array}{l}-0.036 \\
(0.077)\end{array}$ & $\begin{array}{c}0.149^{*} \\
(0.073)\end{array}$ & $\begin{array}{l}-0.110^{*} \\
(0.056)\end{array}$ \\
\hline 6 & $\begin{array}{l}-0.042 \\
(0.049)\end{array}$ & $\begin{array}{l}-0.213 \\
(0.144)\end{array}$ & $\begin{array}{l}-0.274 \\
(0.239)\end{array}$ & $\begin{array}{l}-0.061^{*} \\
(0.033)\end{array}$ & $\begin{array}{l}-0.246^{*} \\
(0.135)\end{array}$ & $\begin{array}{l}-0.600^{*} \\
(0.344)\end{array}$ & N.A. & $\begin{array}{l}-0.105^{\star *} \\
(0.050)\end{array}$ & $\begin{array}{c}0.068^{\star *} \\
(0.027)\end{array}$ & $\begin{array}{l}0.169^{\star *} \\
(0.062)\end{array}$ & $\begin{array}{l}-0.143^{*} \\
(0.083)\end{array}$ \\
\hline \multicolumn{12}{|l|}{ B. } \\
\hline 2 & $\begin{array}{c}0.073 \\
(0.049)\end{array}$ & $\begin{array}{c}0.011 \\
(0.044)\end{array}$ & $\begin{array}{l}-0.002 \\
(0.166)\end{array}$ & $\begin{array}{c}0.088 \\
(0.074)\end{array}$ & $\begin{array}{l}-0.023 \\
(0.102)\end{array}$ & $\begin{array}{l}-0.233 \\
(0.216)\end{array}$ & $\begin{array}{l}0.038^{\star *} \\
(0.014)\end{array}$ & $\begin{array}{l}-0.064 \\
(0.117)\end{array}$ & $\begin{array}{c}0.033 \\
(0.040)\end{array}$ & $\begin{array}{l}0.067^{\star * *} \\
(0.021)\end{array}$ & $\begin{array}{l}-0.006 \\
(0.011)\end{array}$ \\
\hline 3 & $\begin{array}{l}-0.023 \\
(0.060)\end{array}$ & $\begin{array}{c}0.015 \\
(0.061)\end{array}$ & $\begin{array}{l}-0.005 \\
(0.154)\end{array}$ & $\begin{array}{l}-0.017 \\
(0.054)\end{array}$ & $\begin{array}{l}-0.019 \\
(0.099)\end{array}$ & $\begin{array}{l}-0.147 \\
(0.193)\end{array}$ & $\begin{array}{l}0.050^{\star * *} \\
(0.015)\end{array}$ & $\begin{array}{l}-0.165^{\star *} \\
(0.065)\end{array}$ & $\begin{array}{c}0.074^{*} \\
(0.040)\end{array}$ & $\begin{array}{c}0.029 \\
(0.023)\end{array}$ & $\begin{array}{l}-0.055^{\star *} \\
(0.026)\end{array}$ \\
\hline 4 & $\begin{array}{c}0.088 \\
(0.062)\end{array}$ & $\begin{array}{l}-0.122 \\
(0.106)\end{array}$ & $\begin{array}{l}-0.158 \\
(0.109)\end{array}$ & $\begin{array}{c}0.070 \\
(0.048)\end{array}$ & $\begin{array}{l}-0.020 \\
(0.109)\end{array}$ & $\begin{array}{l}-0.129 \\
(0.242)\end{array}$ & $\begin{array}{l}0.033^{* *} \\
(0.013)\end{array}$ & $\begin{array}{l}-0.063 \\
(0.051)\end{array}$ & $\begin{array}{l}-0.024 \\
(0.028)\end{array}$ & $\begin{array}{c}0.078 \\
(0.068)\end{array}$ & $\begin{array}{l}-0.033 \\
(0.053)\end{array}$ \\
\hline 5 & $\begin{array}{l}-0.022 \\
(0.073)\end{array}$ & $\begin{array}{c}0.051 \\
(0.052)\end{array}$ & $\begin{array}{l}-0.010 \\
(0.156)\end{array}$ & $\begin{array}{l}-0.039 \\
(0.045)\end{array}$ & $\begin{array}{c}0.101 \\
(0.061)\end{array}$ & $\begin{array}{l}-0.266 \\
(0.246)\end{array}$ & $\begin{array}{c}0.030 \\
(0.021)\end{array}$ & $\begin{array}{l}-0.117^{\star *} \\
(0.056)\end{array}$ & $\begin{array}{c}0.075^{*} \\
(0.041)\end{array}$ & $\begin{array}{l}0.084^{\star *} \\
(0.037)\end{array}$ & $\begin{array}{l}-0.059 * \\
(0.034)\end{array}$ \\
\hline 6 & $\begin{array}{c}0.016 \\
(0.038)\end{array}$ & $\begin{array}{l}-0.225^{\star} \\
(0.128)\end{array}$ & $\begin{array}{c}-0.199 \\
(0.152)\end{array}$ & $\begin{array}{c}0.025 \\
(0.036) \\
\end{array}$ & $\begin{array}{l}-0.279 * * * \\
(0.097)\end{array}$ & $\begin{array}{c}-0.292 \\
(0.261)\end{array}$ & N.A. & $\begin{array}{l}-0.122^{* *} \\
(0.053)\end{array}$ & $\begin{array}{l}0.108^{\star * *} \\
(0.027)\end{array}$ & $\begin{array}{c}0.103^{\star *} \\
(0.043)\end{array}$ & $\begin{array}{l}-0.190^{\star * *} \\
(0.053)\end{array}$ \\
\hline
\end{tabular}

Note: Each cell represents the weighted least squares estimate from a separate regression, using weights constructed through entropy balancing. Robust standard errors in parentheses are clustered by the national sampling unit. Sample in Panel A excludes children who did not have low birth weight or preterm birth but had other abnormal birth conditions. Sample in Panel $\mathrm{C}$ excludes children who had abnormal birth conditions that were coded as likely to be caused by maternal behavior. SSI = Supplemental Security Income. N.A. = not available because the outcome was not asked about in the survey wave.

${ }^{* * * / * *}$ Statistically significant at the $.10 / .05 / .01$ level. 


\section{VII.CONCLUSION}

Using administrative birth record data combined with a 15-year panel of survey data from the Fragile Families Study, this paper offered a unique examination of the consequences of poor neonatal health among urban families. We show that about one-fifth of infants born among these families are born in poor health, with low birth weight and respiratory difficulties being the most common abnormal birth conditions. Further, we demonstrate that families who have infants born in poor health are different from other families in many dimensions, which suggests that these families are a nonrandom sample. To account for selection bias, we use entropy balancing and weighted least-square estimators to obtain the treatment on the treated effects of poor neonatal health.

In total, the results suggest that the effects of poor neonatal health are substantial. Poor neonatal health may demand so much in time resources that treated mothers are compelled to work less at both the intensive and the extensive margin, especially when the child is younger. Further, children with poor neonatal health are much more likely to be diagnosed with a disability, which in turn leads to higher SSI receipt. Treated households are also more likely to receive benefits from SNAP and TANF. Treated mothers are much less likely to be married or cohabitating with the child's father, relative to the counterfactual, which suggests that the stress from having a child in poor health could lead to ruptures in already "fragile" families. Somewhat reassuringly, treated households are not any more likely to experience poverty or declines in household income, which could be due to the buffering effects of income obtained from safety net programs. We also do not find any significant differences in the likelihood of maternal depression, though we examine only one measure of mental health. Further work is needed to assess whether other aspects of parental mental health are affected.

Our study highlights the broad consequences of poor neonatal health on the family, and suggests that the spillover effects on the family could act as additional pathways through which neonatal health affects adult outcomes. More research is needed to understand whether the provision of follow-up care of infants with poor birth outcomes, especially among low-income populations, can significantly alter health trajectories. This includes further investigation into how best to ensure adequate assessments that allow for timely identification of needs for early intervention services. Further work to shed light on the extent to which perinatal interventions can remediate the disadvantage of poor birth outcomes cancan help guide policy designed to improve outcomes of children with poor neonatal health. Continued research to cast light on the spillover effects of poor birth outcomes and child disability on families, such as parental mental health, are equally needed to understand how best to support these especially vulnerable families. 
This page has been left blank for double-sided copying. 


\section{REFERENCES}

Almond, D., Chay, K. Y., \& Lee, D. S. (2005). The costs of low birth weight. Quarterly Journal of Economics, 120(3), 1031-1083.

American Academy of Pediatrics. (2004). Follow-up care of high-risk infants. Pediatrics, 114(5), 1377-1397.

Black, S. E., Devereux, P. J., \& Salvanes, K. G. (2007). From the cradle to the labor market? The effect of birth weight on adult outcomes. Quarterly Journal of Economics, 122(1), 409-439.

Carlson, B. L. (2008). Fragile families \& child wellbeing study: Methodology for constructing mother, father, and couple weights for core telephone public survey data waves 1-4. Princeton, NJ: Mathematica Policy Research.

Case, A., Lubotsky, D., \& Paxson, C. (2002). Economic status and health in childhood: The origins of the gradient. American Economic Review, 92(5):1308-1334.

Conley, D., Strully, K. W., \& Bennett, N. G. (2006). Twin differences in birth weight: The effects of genotype and prenatal environment on neonatal and post-neonatal mortality. Economics \& Human Biology, 4(2), 151-183.

Corman, H., Noonan, K., \& Reichman, N. E. (2005). Mothers' labor supply in fragile families: The role of child health. Eastern Economic Journal, 31(4), 601-616.

Corman, H., \& Kaestner, R. (1992). The effects of child health on marital status and family structure. Demography, 29(3), 389-408.

Drake, C. (1993). Effects of misspecification of the propensity score on estimators of treatment effect. Biometrics, 49(4), 1231-1236.

Elder, T., Figlio, D. N., Imberman, S. A., \& Persico, C. (2019). The role of neonatal health in the incidence of childhood disability. NBER working paper no. 25828. Cambridge, MA: National Bureau of Economic Research.

Figlio, D., Guryan, J., Karbownik, K., \& Roth, J. (2014). The effects of poor neonatal health on children's cognitive development. American Economic Review, 104(12), 3921-3955.

Fox, A. M., Feng, W., Zeitlin, J., Scruggs, L., Meier, B., Howell, E. (2017). Constructing an index of state safety-net generosity, 1996-2010: Approach and validation. Working paper.

Gould, E. (2004). Decomposing the effects of children's health on mother's labor supply: Is it time or money? Health Economics, 13(6), 525-541.

Guldi, M., Hawkins, A., Hemmeter, J., \& Schmidt, L. (2018). Supplemental Security Income and child outcomes: Evidence from birth weight eligibility cutoffs. NBER working paper no. 24913. Cambridge, MA: National Bureau of Economic Research. 
Hainmueller, J. (2012). Entropy balancing for causal effects: A multivariate reweighting method to produce balanced samples in observational studies. Political Analysis, 20(1), 25-46.

Hainmueller, J., \& Xu, Y. (2013). Ebalance: A Stata package for entropy balancing. Journal of Statistical Software, 54(7).

Hartley, S. L., Barker, E. T., Seltzer, M. M., Floyd, F. J., Orsmond, G. I., Greenberg, . . Bolt, D. (2010). The relative risk and timing of divorce in families of children with an autism spectrum disorder. Journal of Family Psychology, 24(4), 449-457.

Kang, J. D., and Schafer, J. L. (2007) Demystifying double robustness: A comparison of alternative strategies for estimating a population mean from incomplete data. Statistical Science, 22(4), 523-539.

Kim, D., \& Saada, A. (2013). The social determinants of infant mortality and birth outcomes in Western developed nations: A cross-country systematic review. International Journal of Environmental Research and Public Health, 10(6), 2296-2335.

Kuhlthau, K. A., \& Perrin, J. M. (2001). Child health status and parental employment. Archives of Pediatric and Adolescent Medicine, 155(12), 1346-1350.

Luca, D. L., Garlow, N., Staatz, C., Margiotta, C., \& Zivin, K. (2019). Societal costs of untreated perinatal mood and anxiety disorders in the United States. Cambridge, MA: Mathematica Policy Research.

Luca, D. L., \& Sevak, P. (2018). Child Disability, Maternal Labor Supply, and Household WellBeing. Cambridge, MA: Mathematica Policy Research.

MacDorman, M. F., Mathews, T. J., \& DeClercq, E. (2014). Trends in out-of-hospital births in the United States, 1990-2012. Data Brief No. 144. Hyattsville, MD: National Center for Health Statistics.

Morgan, S. L., \& Winship, C. (2015). Counterfactuals and causal inference: Methods and principles for social research (2nd ed.). Cambridge, UK: Cambridge University Press.

Newacheck, P. W., \& Kim, S. E. (2005). A national profile of health care utilization and expenditures for children with special health care needs. Archives of Pediatric and Adolescent Medicine, 159(1), 10-17.

Newacheck, P. W., Halfon, N., \& Budetti, P. P. (1986). Prevalence of activity limiting chronic conditions among children based on household interviews. Journal of Chronic Diseases, 39(2), 63-71.

Normand, S. L. T., Landrum, M. B., Guadagnoli, E., Ayanian, J. Z., Ryan, T. J., Cleary, P. D., \& McNeil, B. J. (2001) Validating recommendations for coronary angiography following an acute myocardial infarction in the elderly: A matched analysis using propensity scores. Journal of Clinical Epidemiology, 54(4), 387-398. 
National Research Council and Institute of Medicine. (2000). From neurons to neighborhoods: The science of early childhood development. Committee on Integrating the Science of Early Childhood Development. Jack P. Shonkoff and Deborah A. Phillips, eds. Board on Children, Youth, and Families, Commission on Behavioral and Social Sciences and Education. Washington, DC: National Academy Press.

Oreopoulos, P., Stabile, M., Walld, R., \& Roos, L. L. (2008). Short-, medium-, and long-term consequences of poor infant health an analysis using siblings and twins. Journal of Human Resources, 43(1), 88-138.

Porterfield, Shirley L., \& Tracey, Colleen. (2003). Disentangling the dynamics of family poverty and child disability: Does disability come first? Washington University, Working Paper No. 03-01. St. Louis, MO: Center for Social Development.

Powers, E. T. (2003). Children's health and maternal work activity estimates under alternative disability definitions. Journal of Human Resources, 38(3), 522-556.

Reichman, N. E., Corman, H., \& Noonan, K. (2004). Effects of child health on parents' relationship status. Demography, 41(3), 569-584.

Reichman, N. E., Corman, H., \& Noonan, K. (2008). Impact of child disability on the family. Maternal and Child Health Journal, 12(6), 679-683.

Reichman, N. E., Corman, H., \& Noonan, K. (2006). Effects of child health on sources of public support. Southern Economic Journal, 73(1), 136-156.

Reichman, N. E., Teitler, J. O., Garfinkel, I., \& McLanahan, S. S. (2001). Fragile families: Sample and design. Children and Youth Services Review, 23(4-5), 303-326.

Ridgeway, G., Kovalchik, S. A., Griffin, B. A., \& Kabeto, M. U. (2015). Propensity score analysis with survey weighted data. Journal of Causal Inference, 3(2), 237-249.

Rosenbaum, P. R., \& Rubin, D. B. (1983). The central role of the propensity score in observational studies for causal effects. Biometrika, 70(1), 41-55.

Rubin, D. B. (2001). Using propensity scores to help design observational studies: Application to the tobacco litigation. Health Services \& Outcomes Research Methodology, 2(3-4), 169-188.

Swaminathan, S., Alexander, G., \& Boulet, S. (2006). Delivering a very low birth weight infant and the subsequent risk of divorce or separation. Maternal and Child Health Journal, 10(6), 473-479.

Van Cleave, J., Gortmaker, S. L., \& Perrin, J. M. (2010). Dynamics of obesity and chronic health conditions among children and youth. Journal of the American Medical Association, 303(7), 623-630. 
This page has been left blank for double-sided copying. 
APPENDIX

SUPPLEMENTARY TABLES 
This page has been left blank for double-sided copying. 


\section{A.1. Impact of poor neonatal health on subsequent child health, OLS results}

\begin{tabular}{|c|c|c|c|c|c|c|c|c|c|c|c|c|}
\hline \multirow{4}{*}{$\begin{array}{l}\text { Wave } \\
2\end{array}$} & & & \multicolumn{10}{|c|}{ Type of disability } \\
\hline & \multicolumn{2}{|c|}{ Any disability } & \multicolumn{2}{|c|}{ Neurodevelopmental } & \multicolumn{2}{|c|}{ Motor } & \multicolumn{2}{|c|}{ Sensory } & \multicolumn{2}{|c|}{ Heart } & \multicolumn{2}{|c|}{ Speech } \\
\hline & $0.055^{* * *}$ & $0.057^{* \star *}$ & 0.003 & 0.001 & $0.009^{* *}$ & $0.008^{*}$ & 0.001 & 0.001 & -0.000 & 0.000 & $N$ & $N$ \\
\hline & $(0.017)$ & $(0.020)$ & $(0.002)$ & $(0.001)$ & $(0.004)$ & $(0.005)$ & $(0.001)$ & $(0.002)$ & $(0.002)$ & $(0.002)$ & N.A. & N.A. \\
\hline \multirow[t]{2}{*}{3} & $0.038^{* * *}$ & $0.047^{\star *}$ & $0.008^{* \star *}$ & $0.008^{* *}$ & $0.024^{*}$ & 0.032 & 0.005 & 0.005 & 0.002 & 0.003 & 0.002 & 0.003 \\
\hline & $(0.012)$ & $(0.020)$ & $(0.002)$ & $(0.003)$ & $(0.012)$ & $(0.020)$ & $(0.003)$ & $(0.004)$ & $(0.002)$ & $(0.003)$ & $-(0.002)$ & $-(0.002)$ \\
\hline \multirow[t]{2}{*}{4} & 0.102 & 0.078 & $0.072^{* \star *}$ & 0.029 & $0.016^{*}$ & $0.013^{*}$ & 0.004 & 0.004 & 0.012 & $0.024^{\star *}$ & 0.068 & 0.058 \\
\hline & $(0.066)$ & $(0.068)$ & $(0.019)$ & $(0.021)$ & $(0.008)$ & $(0.007)$ & $(0.004)$ & $(0.004)$ & $(0.007)$ & $(0.009)$ & $-(0.066)$ & $-(0.054)$ \\
\hline \multirow[t]{2}{*}{5} & $0.038^{*}$ & 0.023 & $0.046^{\star \star \star}$ & $0.046^{* *}$ & 0.009 & 0.009 & 0.001 & $0.006^{*}$ & -0.007 & -0.010 & -0.003 & 0.004 \\
\hline & $(0.020)$ & $(0.034)$ & $(0.016)$ & $(0.020)$ & $(0.008)$ & $(0.007)$ & $(0.003)$ & $(0.003)$ & $(0.005)$ & $(0.010)$ & $-(0.029)$ & $-(0.034)$ \\
\hline \multirow[t]{2}{*}{6} & $0.105^{\star \star *}$ & 0.038 & $0.116^{\star \star \star}$ & $0.061^{* * *}$ & $0.026^{\star *}$ & 0.015 & $\Lambda$ & $\mathrm{N}$ & 0.009 & -0.003 & 0.006 & $0.009^{* *}$ \\
\hline & $(0.030)$ & $(0.032)$ & $(0.037)$ & $(0.022)$ & $(0.011)$ & $(0.014)$ & IV.R. & ה. T. & $(0.011)$ & $(0.015)$ & $-(0.006)$ & $-(0.004)$ \\
\hline Controls & No & Yes & No & Yes & No & Yes & No & Yes & No & Yes & No & Yes \\
\hline
\end{tabular}

Note: $\quad$ Each cell represents the weighted least squares estimate from a separate regression, using only the city sample weights. Controls include baseline covariates used in the entropy-balancing scheme, as well as hospital and state fixed effects. Robust standard errors in parentheses are clustered by the national sampling unit. Sensory disorders include blindness and deafness. Motor disorders include problems with limbs and cerebral palsy.

Neurodevelopmental disorders include developmental, autism, and attention-deficit/hyperactivity disorders.

$* / * * * *$ Statistically significant at the $.10 / .05 / .01$ level. 


\section{A.2. Impact of poor neonatal health on maternal labor market activity, OLS results}

\begin{tabular}{|c|c|c|c|c|c|c|c|c|c|c|c|c|}
\hline \multirow{2}{*}{$\frac{\text { Wave }}{2}$} & \multicolumn{2}{|c|}{$\begin{array}{l}\text { Worked } \\
\text { last week }\end{array}$} & \multicolumn{2}{|c|}{$\begin{array}{l}\text { Hours worked } \\
\text { last week, logged }\end{array}$} & \multicolumn{2}{|c|}{$\begin{array}{l}\text { Earnings last week, } \\
\text { logged }\end{array}$} & \multicolumn{2}{|c|}{$\begin{array}{l}\text { Worked } \\
\text { last year }\end{array}$} & \multicolumn{2}{|c|}{$\begin{array}{l}\text { Hours worked } \\
\text { last year, logged }\end{array}$} & \multicolumn{2}{|c|}{$\begin{array}{c}\text { Earnings last year, } \\
\text { logged }\end{array}$} \\
\hline & 0.033 & 0.042 & -0.042 & -0.035 & 0.421 & 0.344 & 0.051 & $0.068^{*}$ & $-0.250^{* * *}$ & $-0.179^{*}$ & 0.520 & 0.351 \\
\hline & $(0.071)$ & $(0.026)$ & $(0.028)$ & $(0.027)$ & $(0.354)$ & $(0.212)$ & $(0.063)$ & $(0.035)$ & $(0.085)$ & $(0.090)$ & $(0.596)$ & $(0.323)$ \\
\hline \multirow[t]{2}{*}{3} & $-0.108^{\star *}$ & $-0.097^{* *}$ & -0.022 & -0.029 & $-0.413^{*}$ & -0.286 & $-0.076^{\star *}$ & $-0.052^{* *}$ & $-0.123^{*}$ & $-0.143^{*}$ & $-0.749^{*}$ & -0.447 \\
\hline & $(0.043)$ & $(0.035)$ & $(0.034)$ & $(0.037)$ & $(0.233)$ & $(0.177)$ & $(0.036)$ & $(0.024)$ & $(0.062)$ & $(0.078)$ & $(0.407)$ & $(0.273)$ \\
\hline \multirow[t]{2}{*}{4} & -0.023 & 0.033 & $-0.069^{\star}$ & -0.100 & 0.055 & 0.041 & -0.016 & 0.004 & 0.012 & -0.008 & 0.188 & 0.244 \\
\hline & $(0.036)$ & $(0.032)$ & $(0.037)$ & $(0.084)$ & $(0.270)$ & $(0.201)$ & $(0.032)$ & $(0.029)$ & $(0.114)$ & $(0.076)$ & $(0.412)$ & $(0.300)$ \\
\hline \multirow[t]{2}{*}{5} & $-0.060^{\star *}$ & $-0.080^{\star *}$ & 0.041 & 0.017 & 0.031 & -0.146 & -0.022 & -0.036 & 0.065 & 0.098 & 0.037 & -0.140 \\
\hline & $(0.022)$ & $(0.038)$ & $(0.058)$ & $(0.029)$ & $(0.284)$ & $(0.139)$ & $(0.019)$ & $(0.034)$ & $(0.178)$ & $(0.114)$ & $(0.535)$ & $(0.251)$ \\
\hline \multirow[t]{2}{*}{6} & -0.019 & -0.009 & $-0.275^{\star *}$ & $-0.177^{\star *}$ & -0.096 & -0.119 & -0.007 & -0.003 & $-0.163^{\star \star}$ & -0.097 & $-0.694^{\star *}$ & $-0.383^{\star *}$ \\
\hline & $(0.030)$ & $(0.025)$ & $(0.125)$ & $(0.068)$ & $(0.358)$ & $(0.132)$ & $(0.036)$ & $(0.031)$ & $(0.061)$ & $(0.057)$ & $(0.322)$ & $(0.178)$ \\
\hline Controls & No & Yes & No & Yes & No & Yes & No & Yes & No & Yes & No & Yes \\
\hline
\end{tabular}

Note: Each cell represents the weighted least squares estimate from a separate regression, using only the city sample weights. Controls include baseline covariates used in the entropy-balancing scheme, as well as hospital and state fixed effects. Robust standard errors in parentheses are clustered by the national sampling unit. Hours worked are conditional upon working. Earnings are augmented by 1 before logging and include those with zero earnings.

${ }^{* * * / * * *}$ Statistically significant at the $.10 / .05 / .01$ level. 


\section{A.3. Impact of poor neonatal health on benefit receipt, OLS results}

\begin{tabular}{|c|c|c|c|c|c|c|c|c|}
\hline Wave & \multicolumn{2}{|c|}{$\begin{array}{l}\text { Child } \\
\text { SSI }\end{array}$} & \multicolumn{2}{|c|}{ SNAP } & \multicolumn{2}{|c|}{ TANF } & \multicolumn{2}{|c|}{$\begin{array}{l}\text { Other public } \\
\text { assistance }\end{array}$} \\
\hline 2 & $\begin{array}{c}0.029^{\star \star *} \\
(0.010)\end{array}$ & $\begin{array}{l}0.036^{\star *} \\
(0.016)\end{array}$ & $\begin{array}{c}0.009 \\
(0.024)\end{array}$ & $\begin{array}{c}0.009 \\
(0.021)\end{array}$ & $\begin{array}{c}0.012 \\
(0.032)\end{array}$ & $\begin{array}{c}0.007 \\
(0.024)\end{array}$ & $\begin{array}{c}0.017 \\
(0.015)\end{array}$ & $\begin{array}{r}0.026 \\
(0.020)\end{array}$ \\
\hline 3 & $\begin{array}{c}0.049^{* * *} \\
(0.010)\end{array}$ & $\begin{array}{c}0.056^{\star * *} \\
(0.015)\end{array}$ & $\begin{array}{c}0.069 \\
(0.065)\end{array}$ & $\begin{array}{l}0.087^{\star} \\
(0.051)\end{array}$ & $\begin{array}{c}0.022 \\
(0.022)\end{array}$ & $\begin{array}{c}0.026 \\
(0.018)\end{array}$ & $\begin{array}{l}-0.008 \\
(0.024)\end{array}$ & $\begin{array}{l}-0.010 \\
(0.019)\end{array}$ \\
\hline 4 & $\begin{array}{c}0.037^{* * *} \\
(0.011)\end{array}$ & $\begin{array}{l}0.036^{* *} \\
(0.013)\end{array}$ & $\begin{array}{c}0.077^{* \star *} \\
(0.027)\end{array}$ & $\begin{array}{l}0.066^{*} \\
(0.035)\end{array}$ & $\begin{array}{c}0.082^{* * *} \\
(0.023)\end{array}$ & $\begin{array}{l}0.070^{* *} \\
(0.030)\end{array}$ & $\begin{array}{c}0.003 \\
(0.022)\end{array}$ & $\begin{array}{l}-0.001 \\
(0.027)\end{array}$ \\
\hline 5 & $\begin{array}{c}0.024^{* * *} \\
(0.009)\end{array}$ & $\begin{array}{l}0.028^{* *} \\
(0.013)\end{array}$ & $\begin{array}{c}0.070^{* * *} \\
(0.017)\end{array}$ & $\begin{array}{l}0.050^{* *} \\
(0.023)\end{array}$ & $\begin{array}{l}-0.013 \\
(0.050)\end{array}$ & $\begin{array}{l}-0.002 \\
(0.025)\end{array}$ & $\begin{array}{c}0.014 \\
(0.011)\end{array}$ & $\begin{array}{l}-0.004 \\
(0.010)\end{array}$ \\
\hline 6 & N.A. & N.A. & $\begin{array}{c}0.045^{\star} \\
(0.026)\end{array}$ & $\begin{array}{c}0.012 \\
(0.021)\end{array}$ & $\begin{array}{l}0.033^{* *} \\
(0.016)\end{array}$ & $\begin{array}{c}0.019 \\
(0.028)\end{array}$ & $\begin{array}{l}-0.010 \\
(0.011)\end{array}$ & $\begin{array}{l}-0.005 \\
(0.011)\end{array}$ \\
\hline Controls & No & Yes & No & Yes & No & Yes & No & Yes \\
\hline
\end{tabular}

Note: $\quad$ Each cell represents the weighted least squares estimate from a separate regression, using only the city sample weights. Controls include baseline covariates used in the entropy-balancing scheme, as well as hospital and state fixed effects. Robust standard errors in parentheses are clustered by the national sampling unit.

${ }^{\star / * \star / * \star}$ Statistically significant at the $.10 / .05 / .01$ levels.

\section{A.4. Impact of poor neonatal health on household well-being, OLS results}

\begin{tabular}{|c|c|c|c|c|c|c|c|c|}
\hline \multirow{2}{*}{$\begin{array}{l}\text { Wave } \\
2\end{array}$} & \multicolumn{2}{|c|}{$\begin{array}{c}\text { Household income, } \\
\text { logged }\end{array}$} & \multicolumn{2}{|c|}{$\begin{array}{l}\text { Household } \\
\text { poverty }\end{array}$} & \multicolumn{2}{|c|}{$\begin{array}{l}\text { Mom experienced } \\
\text { depression }\end{array}$} & \multicolumn{2}{|c|}{$\begin{array}{l}\text { Parents married or } \\
\text { cohabitating }\end{array}$} \\
\hline & $\begin{array}{l}-0.012 \\
(0.174)\end{array}$ & $\begin{array}{l}-0.043 \\
(0.093)\end{array}$ & $\begin{array}{c}0.006 \\
(0.054)\end{array}$ & $\begin{array}{c}0.020 \\
(0.031)\end{array}$ & $\begin{array}{c}0.003 \\
(0.024)\end{array}$ & $\begin{array}{c}0.006 \\
(0.025)\end{array}$ & $\begin{array}{c}-0.057^{\star * \star} \\
(0.014)\end{array}$ & $\begin{array}{c}-0.048^{\star *} \\
(0.019)\end{array}$ \\
\hline 3 & $\begin{array}{l}-0.043 \\
(0.190)\end{array}$ & $\begin{array}{l}-0.062 \\
(0.119)\end{array}$ & $\begin{array}{c}0.048 \\
(0.051)\end{array}$ & $\begin{array}{l}0.052^{*} \\
(0.028)\end{array}$ & $\begin{array}{c}0.032 \\
(0.032)\end{array}$ & $\begin{array}{c}0.022 \\
(0.021)\end{array}$ & $\begin{array}{c}-0.060^{* \star *} \\
(0.019)\end{array}$ & $\begin{array}{l}-0.038^{*} \\
(0.019)\end{array}$ \\
\hline 4 & $\begin{array}{c}0.022 \\
(0.107)\end{array}$ & $\begin{array}{c}0.047 \\
(0.071)\end{array}$ & $\begin{array}{l}-0.047 \\
(0.076)\end{array}$ & $\begin{array}{l}-0.039 \\
(0.049)\end{array}$ & $\begin{array}{l}0.031^{*} \\
(0.017)\end{array}$ & $\begin{array}{c}0.013 \\
(0.016)\end{array}$ & $\begin{array}{l}-0.050 \\
(0.032)\end{array}$ & $\begin{array}{l}-0.009 \\
(0.031)\end{array}$ \\
\hline 5 & $\begin{array}{c}0.021 \\
(0.184)\end{array}$ & $\begin{array}{l}-0.092 \\
(0.110)\end{array}$ & $\begin{array}{c}0.031 \\
(0.022)\end{array}$ & $\begin{array}{l}0.062^{* *} \\
(0.025)\end{array}$ & $\begin{array}{l}-0.002 \\
(0.015)\end{array}$ & $\begin{array}{c}0.014 \\
(0.022)\end{array}$ & $\begin{array}{l}-0.072^{* * *} \\
(0.020)\end{array}$ & $\begin{array}{l}-0.032 \\
(0.037)\end{array}$ \\
\hline 6 & $\begin{array}{c}0.004 \\
(0.109)\end{array}$ & $\begin{array}{l}-0.015 \\
(0.046)\end{array}$ & $\begin{array}{c}0.065^{* * \star} \\
(0.019)\end{array}$ & $\begin{array}{l}0.057^{\star * *} \\
(0.020)\end{array}$ & $\begin{array}{l}0.016^{*} \\
(0.009)\end{array}$ & $\begin{array}{c}0.016 \\
(0.013)\end{array}$ & $\begin{array}{l}-0.073^{* *} \\
(0.035)\end{array}$ & $\begin{array}{l}-0.027 \\
(0.025)\end{array}$ \\
\hline Controls & No & Yes & No & Yes & No & Yes & No & Yes \\
\hline
\end{tabular}

Note: $\quad$ Each cell represents the weighted least squares estimate from a separate regression, using only the city sample weights. Controls include baseline covariates used in the entropy-balancing scheme, as well as hospital and state fixed effects. Robust standard errors in parentheses are clustered by the national sampling unit.

${ }^{\star / * \star / * \star}$ Statistically significant at the $.10 / .05 / .01$ levels. 
This page has been left blank for double-sided copying. 
DATA APPENDIX 
This page has been left blank for double-sided copying. 
This appendix describes in detail how we constructed several key outcome measures.

\section{A. Child disability}

We constructed a binary indicator for whether or not the focal child had a disability at the time of the interview. Because parents did not report the child's disability status during the baseline interview, this variable was not constructed for the wave 1 (birth). Wave 2 asked about the focal child's disability status in the mother and father surveys. Our construct favored the mother's response but used the father's response if the mother's was unavailable. All other waves reported the child's disability or health condition status in the primary caregiver survey.

The survey questions where respondents reported the child's disability status varied across waves (Table B.1). The wave 2 and wave 3 surveys asked about the focal child's disability status through two questions:

1. Does (CHILD) have any physical disabilities?

2. What type of physical disability does he/she have?

If respondents answered "yes," they had the opportunity to answer question 2 and circle as many conditions that apply. Note that although the question specified "physical disability," the listed conditions included intellectual disabilities, such as developmental disorders. Conditions listed varied across waves (Table 2).

The question in waves 4 to 6 differs from this structure in two ways. First, instead of asking the parents to self-report physical disabilities present in their child, the survey in waves 4 to 6 asks respondents if a doctor or health professional has told the respondent that their child has a health condition. Second, the surveys in waves 4 to 6 eliminated the up-front binary question and instead collected information on a series of specific health conditions.

The varied question structure across waves has implications for how we constructed our physical disability variable. For waves 2 and 3, we used the binary variable to construct our child disability indicator. For waves 4 to 6 , we used the series of questions that listed health conditions to construct the indicator.

\section{Table B.1. Child disability survey questions across waves}

\begin{tabular}{|c|c|c|c|c|}
\hline & Wave 1 & Wave 3 & Wave 5 & Wave 6 \\
\hline Question & $\mathrm{n} / \mathrm{a}$ & $\begin{array}{l}\text { Does (CHILD) have any physical } \\
\text { disabilities? }\end{array}$ & $\begin{array}{l}\text { Has a doctor or health } \\
\text { professional ever told } \\
\text { you that (CHILD) has } \\
\text { any of the following } \\
\text { health conditions? }\end{array}$ & $\begin{array}{l}\text { Has a doctor or health } \\
\text { professional ever told } \\
\text { you that }\{\text { YOUTH\} has } \\
\text { any of the following } \\
\text { conditions? }\end{array}$ \\
\hline Survey & $\mathrm{n} / \mathrm{a}$ & $\begin{array}{l}\text { Mother survey } \\
\text { and Father } \\
\text { survey }\end{array}$ & survey & \\
\hline
\end{tabular}

Source: Fragile Families \& Child Wellbeing Study baseline and year 1 mother and father surveys, and year 3, year 5 , year 9 , and year 15 primary caregiver surveys. 
Table B. 2 shows the conditions included in the child disability variable across waves. Note that certain conditions are not included in all waves. The wave 6 survey does not ask respondents whether the focal child has cerebral palsy, blindness, deafness, or Down syndrome. We considered cerebral palsy and Down syndrome to be permanent and extrapolated responses from previous waves to wave 6 . We considered deafness and blindness to be permanent if the child reported the same conditions consistently in previous waves.

Table B.2. Conditions included in child disability variable across waves

\begin{tabular}{|c|c|c|c|c|c|c|}
\hline & Wave 1 & Wave 2 & Wave 3 & Wave 4 & Wave 5 & Wave 6 \\
\hline Cerebral palsy & & $\checkmark$ & $\checkmark$ & $\checkmark$ & $\checkmark$ & a \\
\hline Blindness & & $\checkmark$ & $\checkmark$ & $\checkmark$ & $\checkmark$ & a \\
\hline Deafness & & $\checkmark$ & $\checkmark$ & $\checkmark$ & $\checkmark$ & a \\
\hline Down syndrome & & $\checkmark$ & $\checkmark$ & $\checkmark$ & $\checkmark$ & a \\
\hline Problem with limbs & & $\checkmark$ & $\checkmark$ & $\checkmark$ & $\checkmark$ & $\checkmark$ \\
\hline Other & & $\checkmark$ & $\checkmark$ & & & $\checkmark$ \\
\hline Heart disease & & $\sqrt{b}$ & $\checkmark \mathrm{b}$ & $\checkmark$ & $\checkmark$ & $\checkmark$ \\
\hline Developmental disorder & & $\checkmark b$ & $\checkmark b$ & $\checkmark$ & $\checkmark$ & $\checkmark$ \\
\hline Autism or Asperger syndrome ${ }^{c}$ & & & & $\checkmark$ & $\checkmark$ & $\checkmark$ \\
\hline Speech or language problem & & & $\checkmark$ b & $\checkmark$ & $\checkmark$ & \\
\hline $\begin{array}{l}\text { Attention deficit disorder or attention- } \\
\text { deficit/hyperactivity disorder }\end{array}$ & & & & $\checkmark$ & $\checkmark$ & $\checkmark$ \\
\hline Blood condition (e.g., anemia, leukemia) & & & & $\checkmark$ & $\checkmark$ & $\checkmark$ \\
\hline Depression or anxiety & & & & & & $\checkmark$ \\
\hline Diabetes & & & & & $\checkmark$ & $\checkmark$ \\
\hline Seizures & & & & $\checkmark$ & $\checkmark$ & $\checkmark$ \\
\hline
\end{tabular}

Source: Fragile Families \& Child Wellbeing Study baseline and year 1 mother and father surveys, and year 3, year 5 , year 9 , and year 15 primary caregiver surveys.

Note: Respondents were not asked about their child's disability status in the baseline survey.

aThe Wave 6 survey did not ask respondents about their child's cerebral palsy, blindness, deafness, or Down syndrome status. For the purpose of variable construction, these conditions are considered to be permanent and

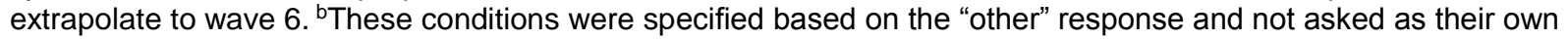
survey questions. "Waves 4,5 , and 6 asked respondents whether a doctor or health professional told them that their child had autism. The wave 6 survey included Asperger syndrome in the autism response option.

We also further grouped the disabilities into categories: sensory (blindness and deafness), neurodevelopmental (developmental, autism, attention-deficit/hyperactivity disorder), motor (cerebral palsy and problem with limbs). We considered speech and heart disorders as individual categories.

\section{B. Mother's earning from all jobs last year, survey response}

We constructed the mother's earnings from all jobs last year using the following survey question and probe from the mother survey:

1. About how much did you earn from (all of) your regular job(s) in the last 12 months? Please do not count any earnings from off-the-books or under-the-table jobs.

2. I just need to have a range. Can you tell me if it was (1) less than $\$ 5,000$ (2) $\$ 5,001$ to $\$ 10,000$ (3) $\$ 10,001$ to $\$ 15,000$ (4) $\$ 15,001$ to $\$ 20,000$ (5) $\$ 20,001$ to $\$ 25,000$ (6) $\$ 25,001$ to $\$ 30,000$ (7) $\$ 30,001$ to $\$ 40,000$ (8) $\$ 40,001$ to $\$ 60,000$ (9) More than $\$ 60,000$ ? 
The question wording and structure was consistent across all six waves and was from the mother's survey. We used the responses from the first question when available, and when not, we used the midpoint of the range reported in the second question. Respondents who never worked for two consecutive weeks or had never worked since the focal child was born skipped this question and were assigned a value of zero for this variable. We conducted some simple top and bottom coding to the earnings measures, determined by being five standard deviations from the mean, and adjusted to 2017 dollars using the CPI-U index of the Bureau of Labor Statistics.

\section{Household income}

We use the household income measure constructed by the Fragile Families survey team at the Center for Research on Child Wellbeing. We provide a brief description here of how the measure was constructed, and further details can be found in the Fragile Families data documentation. The survey asks both parents to report their household income using the following question and probe. Respondents were instructed to include the income of everyone living in the household, money earned from jobs, rent, interest, dividends, and public assistance programs when reporting their total household income.

1. What was your total household income for the last year before taxes?

2. I just need to know a range. Can you tell me if it was (1) $\$ 4,999$ or less (2) $\$ 5,000$ to $\$ 9,999$

(3) $\$ 10,000$ to $\$ 14,999$ (4) $\$ 15,000$ to $\$ 19,999$ (5) $\$ 20,000$ to $\$ 24,999$ (6) $\$ 25,000$ to $\$ 34,999$ (7) $\$ 35,000$ to $\$ 49,999$ (8) $\$ 50,000$ to $\$ 74,999$ (9) Greater than $\$ 75,000$

For married and cohabitating couples, the household income measure was based on the mother's report of income; if the mother's was unavailable, the father's was used. For those who provided bracketed household income at baseline, we imputed household income using the mean value of the bracket. If neither parent reported income, we imputed household income using Stata's regression-based impute command and a number of covariates for mothers and fathers: city, age, years of education, race/ethnicity, earnings, immigrant status, employed last year, hours worked, total adults in household, earnings, received welfare, and marital status. For couples that were not married or cohabitating, the mother or father report was used if available; otherwise, we imputed missing data using the same method and covariates as for married and cohabitating couples. For father-constructed baseline household income, mother reports were used if the couple was married or cohabitating, with the exception of marital status. The percentage imputed varies by wave, ranging from 4.1 percent to 6.9 percent across waves 2 to 6 . We imputed household income for 17 percent of the sample in wave 1 (baseline sample), but we do not use data from the baseline wave for our analysis. We conducted similar top and bottom coding to the income measures, determined by being five standard deviations from the mean, and adjusted to 2017 dollars using the CPI-U index published by the Bureau of Labor Statistics.

\section{Reference}

"The Introduction to the Fragile Families Public Use Data: Baseline, One-Year, Three-Year, and Five-Year Core Telephone Data." Prepared by the staff at the Bendheim-Thoman Center for Research on Child Wellbeing, Princeton University. Retrieved from: http://www.fragilefamilies.princeton.edu/ 
This page has been left blank for double-sided copying. 
www.mathematica-mpr.com

Improving public well-being by conducting high quality, objective research and data collection

PRINCETON, NJ | ANN ARBOR, MI | CAMBRIDGE, MA | CHICAGO, IL | OAKLAND, CA TUCSON, AZ - SEATTLE, WA - WASHINGTON, DC - WOODLAWN, MD

\section{MATHEMATICA CENTER FOR} STUDYING DISABILITY POLICY

Mathematica ${ }^{\circledast}$ is a registered trademark

of Mathematica Policy Research, Inc. 